Research Paper

\title{
Mortality risk of COVID-19 in elderly males with comorbidities: a multi-country study
}

\author{
Guangdi Li ${ }^{1,2}$, Yacong Liu ${ }^{2}$, Xixi Jing ${ }^{2}$, Yali Wang ${ }^{2}$, Miao Miao², Li Tao ${ }^{3}$, Zhiguo Zhou ${ }^{4}$, Yuanlin Xie ${ }^{5}$, \\ Yaxiong Huang ${ }^{4}$, Jianhua Lei ${ }^{1}$, Guozhong Gong ${ }^{1}$, Ping Jin ${ }^{6}$, Yuantao Hao ${ }^{7}$, Nuno Rodrigues Faria ${ }^{8,9}$, \\ Erik De Clercq $^{10}$, Min Zhang $^{1}$
}

${ }^{1}$ Institute of Hepatology and Department of Infectious Diseases, The Second Xiangya Hospital, Central South University, Changsha, China

${ }^{2}$ Hunan Provincial Key Laboratory of Clinical Epidemiology, Xiangya School of Public Health, Central South

University, Changsha, China

${ }^{3}$ School of Mathematics and Statistics, Central South University, Changsha, China

${ }^{4}$ The First Hospital of Changsha, Changsha, China

${ }^{5}$ The Fourth Hospital of Changsha, Changsha, China

${ }^{6}$ Department of Endocrinology, The Third Xiangya Hospital, Central South University, Changsha, China

${ }^{7}$ Department of Medical Statistics and Epidemiology, School of Public Health, Sun Yat-sen University, Guangzhou, China

${ }^{8}$ Department of Zoology, University of Oxford, Oxford, UK

${ }^{9}$ Department of Infectious Disease Epidemiology, School of Public Health, Imperial College London, London, UK

${ }^{10}$ Department of Microbiology, Immunology and Transplantation, Rega Institute for Medical Research, KU Leuven, Leuven, Belgium

Correspondence to: Min Zhang; email: zhangmin001@csu.edu.cn

Keywords: COVID-19, SARS-CoV-2, mortality, risk factors, comorbidities

Received: July 30, $2020 \quad$ Accepted: December 9, 2020 Published: December 31, 2020

Copyright: (c) 2020 Li et al. This is an open access article distributed under the terms of the Creative Commons Attribution License (CC BY 3.0), which permits unrestricted use, distribution, and reproduction in any medium, provided the original author and source are credited.

\section{ABSTRACT}

The COVID-19 pandemic causes severe morbidity and mortality. This multi-country study aimed to explore risk factors that drive mortality in COVID-19 patients who received neither dexamethasone nor remdesivir. We analyzed a cohort of 568 survivors and 507 non-survivors from China, European regions, and North America. Elderly males $\geq 70$ years accounted for only $25 \%$ of survivors, but this rate was significantly higher in nonsurvivors from China (55\%), European regions (63\%), and North America (47\%). Compared with survivors, nonsurvivors had more incidences of comorbidities such as cerebrovascular disease and chronic obstructive pulmonary disease (COPD, p-values<0.05). Survival analyses revealed age, male gender, shortness of breath, cerebrovascular disease, and COPD as mortality-associated factors. Survival time from symptom onset was significantly shorter in elderly versus young patients (median: 29 versus 62 days), males versus females (median: 46 versus 59 days), and patients with versus without comorbidities (mean: 41 versus 61 days). Mortality risk was higher in elderly males with comorbidities than in young females without comorbidities ( $p$ value<0.01). Elderly male survivors with comorbidities also had longer hospital stays than other survivors (25 versus 18.5 days, $p$-value<0.01). Overall, the high mortality risk in elderly males with COVID-19-associated comorbidities supports early prevention and critical care for elderly populations. 


\section{INTRODUCTION}

Coronavirus Disease 2019 (COVID-19) is a global pandemic that is causing significant, widespread increases in morbidity and mortality, while effective antiviral treatments are still under development [1]. As of November $26^{\text {th }}, 2020$, there were more than 60.4 million cases of COVID-19, and the overall casefatality risk was approximately $2.4 \%$ according to an update by the World Health Organization (WHO). With a strong potential of sustained human-to-human transmission, severe acute respiratory syndrome coronavirus 2 (SARS-CoV-2) can quickly spread to vulnerable populations such as elderly individuals with aging-related immune disorders.

Early studies of COVID-19-associated mortality and risk factors have mostly involved small cohorts of non-survivors in Wuhan [2-7]. For instance, COVID19 -associated mortality was observed in $32(62 \%)$ of 52 critically ill patients in Wuhan who received medical care in the intensive care unit [2]. A singlecenter study reported an increased risk of mortality in COVID-19 patients who were severely or critically ill at hospitalization [3]. Additionally, mortality was observed in both non-severe (1.1\%) and severe (32.5\%) patients during the 32-day follow-up [4]. A retrospective study of 54 non-survivors showed the increasing odds of death in association with older age, a high sequential organ failure assessment score, and high d-dimer levels at baseline [5]. Another study in Wuhan reported strong associations of older ages with a high risk of acute respiratory distress syndrome and death [6]. Moreover, $\mathrm{CD} 3^{+} \mathrm{CD} 8^{+} \mathrm{T}$ cells and cardiac troponin I were found to be important risk factors based on a small cohort of 21 non-survivors and 158 survivors [7]. Despite the above findings, it remains unclear why some patients are more susceptible to a fatal outcome of COVID-19 and whether elderly patients outside Wuhan harbor unique features with regard to mortality.

To reveal mortality-associated factors, our study collected a large cohort of survivors who recovered from COVID-19 and non-survivors who died of the disease before May 1, 2020. Due to the authorization of remdesivir on May 1 and dexamethasone on June 17 that may affect our results of mortality-related factors, our data collection initially retrieved clinical records of COVID-19 patients who received neither remdesivir nor dexamethasone. By using epidemiological and clinical records of COVID-19 patients from different countries, this multi-country study revealed a high-risk population of elderly patients with specific comorbidities. Given the rapid spread of COVID-19 which is causing high morbidity and mortality worldwide, a special focus on elderly patients with specific comorbidities in current COVID-19 guidelines should be implemented.

\section{RESULTS}

\section{Epidemiological features}

This study retrieved a multi-country dataset of 1075 COVID-19 patients, including 232 survivors and 183 non-survivors in China, 208 survivors and 258 nonsurvivors in European regions, and 128 survivors and 66 non-survivors in North America (Table 1). None of the COVID-19 patients received remdesivir or dexamethasone - two approved drugs that may potentially reduce the mortality rate of COVID-19 [8, 9]. All COVID-19 patients were reported between January and April 2020. Our workflow and data summary are provided in Figure 1.

We analyzed the age distribution of the 1075 patients in our dataset (Figure 2A). The youngest and oldest nonsurvivors died at 5 and 99 years of age, respectively. COVID-19 survivors were significantly younger than non-survivors in China (median: 64 versus 71 years, p-value $<0.001$, Figure 2B), European regions (60 versus 75 , p-value $<0.001$, Figure $2 \mathrm{C}$ ), and North America (46 versus 71, p-value $<0.001$, Figure 2D). Elderly males $\geq 70$ years accounted for only $25 \%$ of 568 survivors, but this rate was significantly higher among non-survivors from China $(55 \%$, p-value $<0.01)$, European regions $(63 \%$, p-value $<0.01)$, and North America (47\%, p-value $<0.01)$.

Our gender analysis suggested that COVID-19 killed more males than females across China, European regions, and North America (Table 1). The proportion of males was significantly higher among non-survivors than survivors in China (64\% versus 47\%, p-value $<0.01$ ), European regions $(66 \%$ versus $56 \%$, p-value $=0.041)$, and North America (68\% versus 48\%, p-value $=0.01$ ), but such differences were not observed between three sampling origins of non-survivors ( $\mathrm{p}$-values $>0.05$, Table 1).

\section{Clinical features of survivors and non-survivors}

We analyzed the proportions of those with pre-existing comorbidities in a subset of 359 survivors and 239 nonsurvivors whose comorbidities were recorded (Figure 1). As expected, proportions of comorbidities increased with age in males and females, though comorbidity proportions were slightly higher (but insignificant) in males than in females (Figure 3A and Supplementary Table 1). Moreover, non-survivors had higher proportions of comorbidities than survivors aged from 
Table 1. Basic information of 1075 COVID-19 patients in our study.

\begin{tabular}{lcccc}
\hline & & Sample size & Male, n (\%) & Age, median (IQR) \\
\hline \multirow{3}{*}{ Survivors } & China & 232 & $108(47 \%)$ & 64 (54 to 71) \\
& European regions & 208 & $117(56 \%)$ & $59(46$ to 71$)$ \\
& North America & 128 & $61(48 \%)$ & $46(39$ to 53) \\
\hline \multirow{3}{*}{ Non-survivors } & China & 183 & $117(64 \%)$ & $71(64$ to 79$)$ \\
& European regions & 258 & $169(66 \%)$ & $75(66$ to 84) \\
& North America & 66 & $45(68 \%)$ & 71 (56 to 77) \\
\hline
\end{tabular}

IQR: interquartile range.

30 to $\geq 80$ years (Figure 3B). Compared with survivors, non-survivors harbored more comorbidities such as cerebrovascular disease $(2 \%$ versus $8 \%, \mathrm{p}$-value $<0.01)$, cardiovascular disease ( $24 \%$ versus $39 \%$, p-value $<0.01$ ), and chronic obstructive pulmonary disease (COPD, $1 \%$ versus $9 \%$, p-value $<0.01$, Supplementary Table 1 ). In the analysis of comorbidity numbers, more non-survivors had $\geq 3$ comorbidities than survivors $(6 \%$ versus $16 \%$, pvalue $=0.01$, Supplementary Table 1 ). Hypertension was highly prevalent among male non-survivors than male survivors ( $41 \%$ versus $27 \%$, p-value $=0.006$, Figure $3 C$ ).

We next analyzed baseline findings of computed tomography (CT) scans. Incidences of ground-glass opacity, pleural adhesions, and pleural effusion were significantly higher in non-survivors than in survivors (p-values $<0.05$ ). Figure 4 highlights the $\mathrm{CT}$ results of a non-survivor who had abnormal bilateral lungs with ground-glass opacities and pleural adhesions.

Death-related complications were recorded in a subset of 102 non-survivors. The most common complications were respiratory failure $(51 \%)$, acute respiratory distress syndrome $(28.4 \%)$, multiple organ failure (27.5\%), shock $(22.5 \%)$, and hypoxia $(13.7 \%)$. Males and females had similar incidences of death-related complications (Supplementary Table 2).

\section{Risk factors associated with COVID-19 mortality}

To reveal mortality-associated factors, we examined a subset of 242 survivors and 157 non-survivors whose records contained complete information regarding age, gender, comorbidities, symptoms, clinical outcomes, and survival time from symptom onset to clinical outcomes (Figure 1). As shown in Table 2, the most common symptoms at baseline were fever, cough, shortness of breath, and fatigue (proportions $\geq 25 \%$ ). In the comparison of survivors and non-survivors, significant differences in patient age, male gender, shortness of breath, any comorbidity, cerebrovascular disease, cardiovascular disease, chronic liver disease, and COPD were detected (Table 2).
We next used Cox proportional hazards models to evaluate time-dependent hazards of baseline factors for the clinical outcome of death. Univariate Cox regression analyses revealed seven risk factors: age, male gender, shortness of breath, any comorbidity, cerebrovascular disease, cardiovascular disease, and COPD (pvalues $<0.05$, Table 3). Multivariate Cox regression analyses further confirmed five significant factors: male gender (hazard ratio (HR): 1.41, p-value $=0.039$ ), age (HR: 1.03, p-value<0.01), shortness of breath (HR: 1.74 , p-value $=0.0008$ ), cerebrovascular disease (HR: 3.28, p-value<0.01), and COPD (HR: 2.19, pvalue $=0.03$, Table 3 ). These five factors with the effect size of Cohen's $d \geq 0.4$ remained significant in the propensity score-matched samples that potentially reduced the confounding effect (Table 4).

A tree model was built in Figure 5 to visualize proportions of survivors and non-survivors based on 8 possible conditions of three pre-existing factors at baseline: age $(<70$ or $\geq 70$ years), gender (male or female), and any comorbidity (yes or no). Among the 8 possible conditions, the highest proportion of mortality was observed in elderly males with comorbidities (28\%, 44/157), whereas the highest proportion of survivors was found in young females without comorbidities $(18 \%, 44 / 242)$. A higher proportion of non-survivors was often found among males, those $\geq 70$ years, and/or those with comorbidities than among females, those $<70$ years, and/or those without comorbidity (Figure 5). Similar patterns were also observed in the tree models of age, gender plus either cerebrovascular disease or COPD (Supplementary Figure 1).

\section{Impact of risk factors on survival time and length of hospital stay}

Kaplan-Meier curves were evaluated to understand whether risk factors such as age, gender, and comorbidities affect survival time from symptom onset to death - the primary endpoint of clinical outcomes. As shown in Figure 6A, the median survival time of elderly patients $\geq 70$ years was significantly shorter than that of 


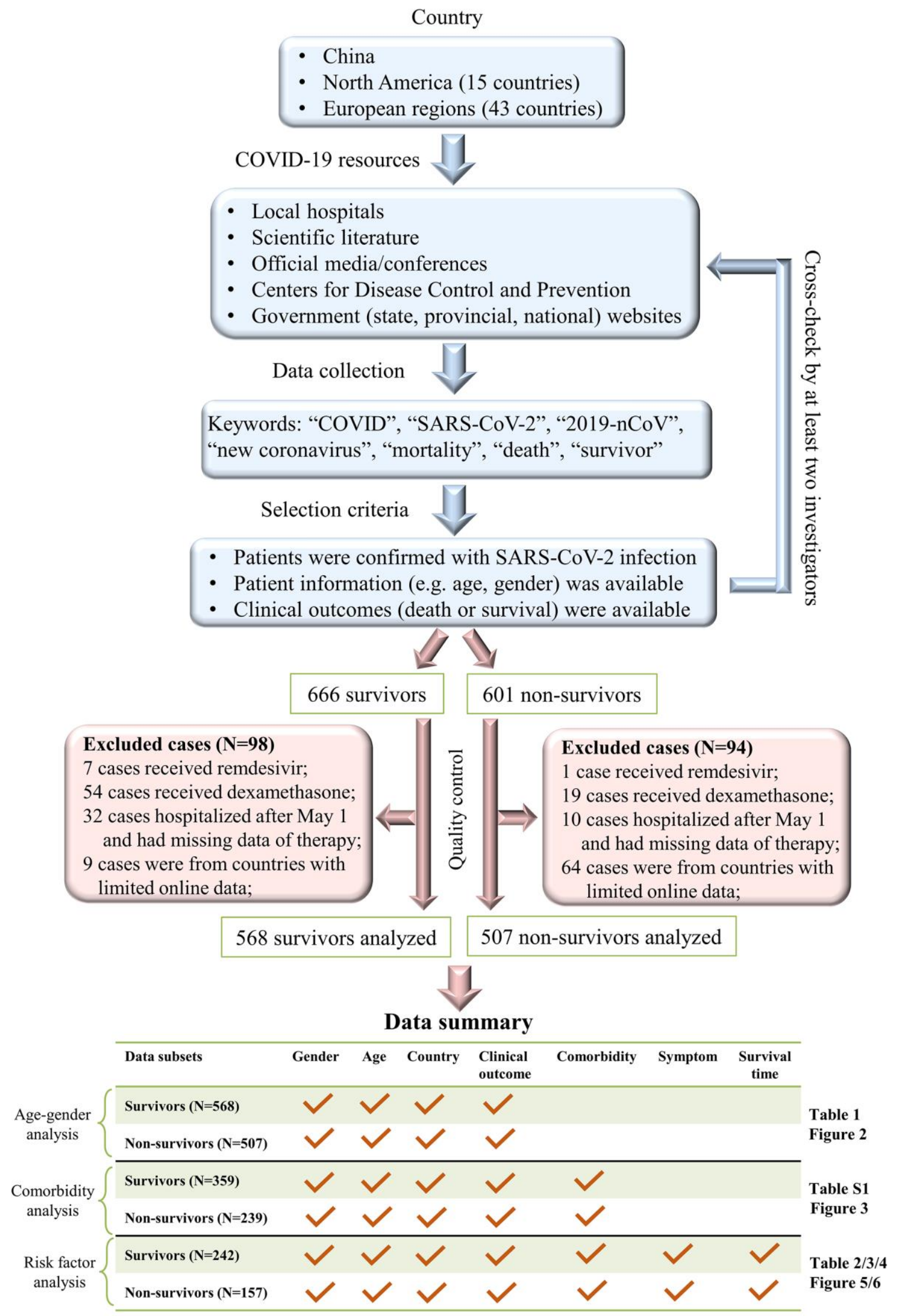

Figure 1. A workflow of our data collection procedures and dataset summary. 


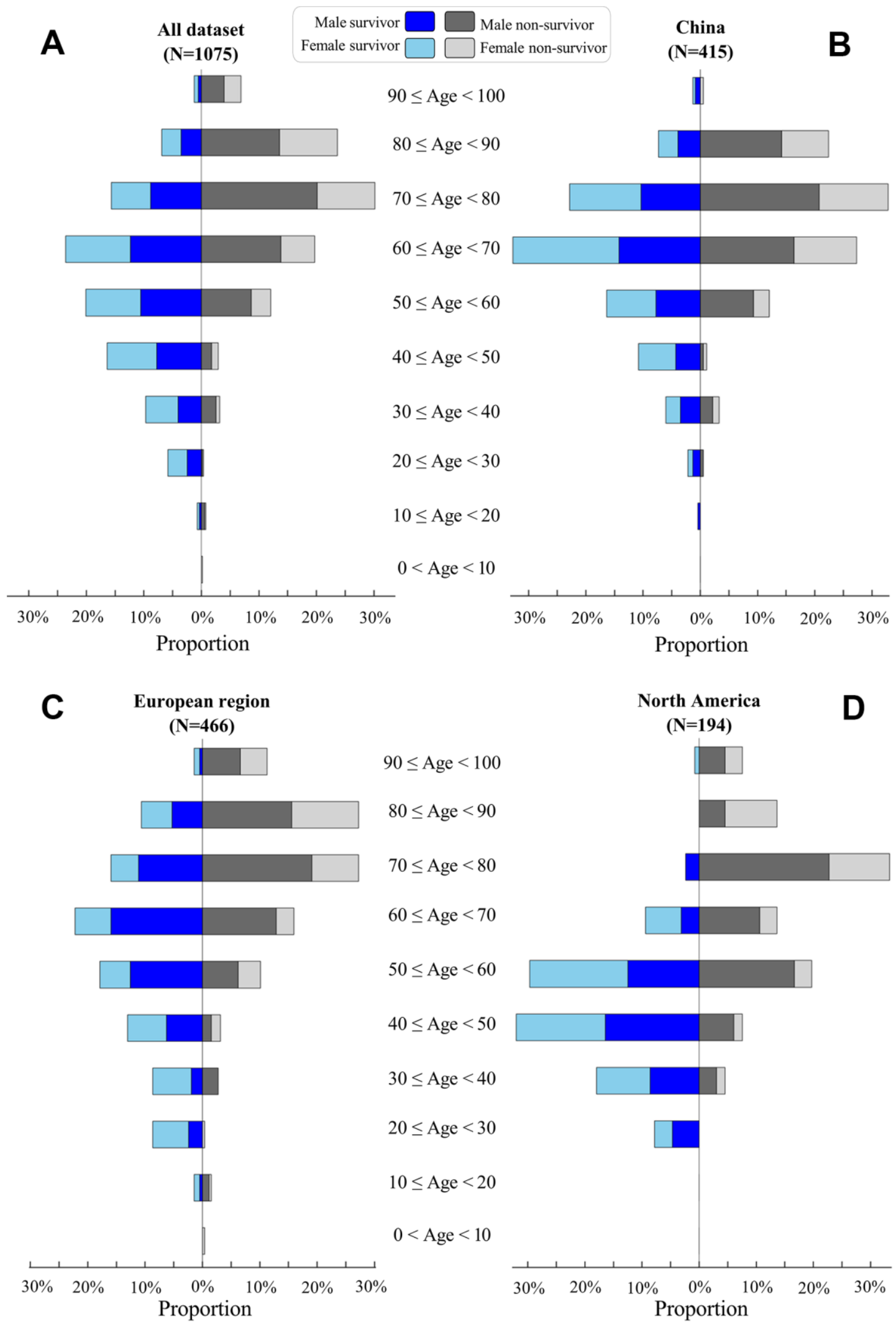

Figure 2. Age distribution of COVID-19 patients. Proportions of survivors (left) and non-survivors (right) at different age classes are visualized for all patients (A), patients in China (B), patients in European regions (C), and patients in North America (D). For survivors, male and female proportions are visualized by blue and light-blue, respectively. For non-survivors, male and female proportions are visualized by black and gray, respectively. 
patients $<70$ years (median: 29 versus 62 days, pvalue $<0.001)$. Male patients had a shorter survival time than female patients (median: 46 versus 59 days, pvalue $=0.021$, Figure $6 \mathrm{~B}$ ). The survival time of patients with comorbidities was shorter than those without any comorbidity (mean: 41 versus 61 days, $p$-value $=0.001$,
Figure 6C). Furthermore, the survival time of patients with $\geq 3$ comorbidities (mean: 27, IQR: 20 to 33 days) was shorter than those with 1 or 2 comorbidities (mean: 43, IQR: 40 to 46.5 days) and those without any comorbidity (mean: 60, IQR: 55 to 66 days, pvalues $<0.01$, Supplementary Figure 2A). Patients with

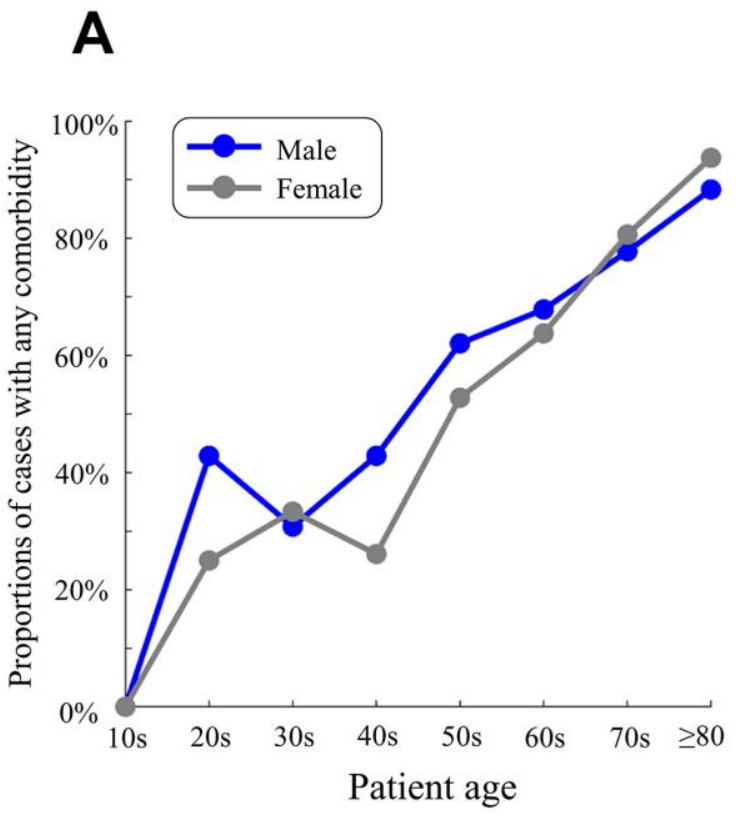

B
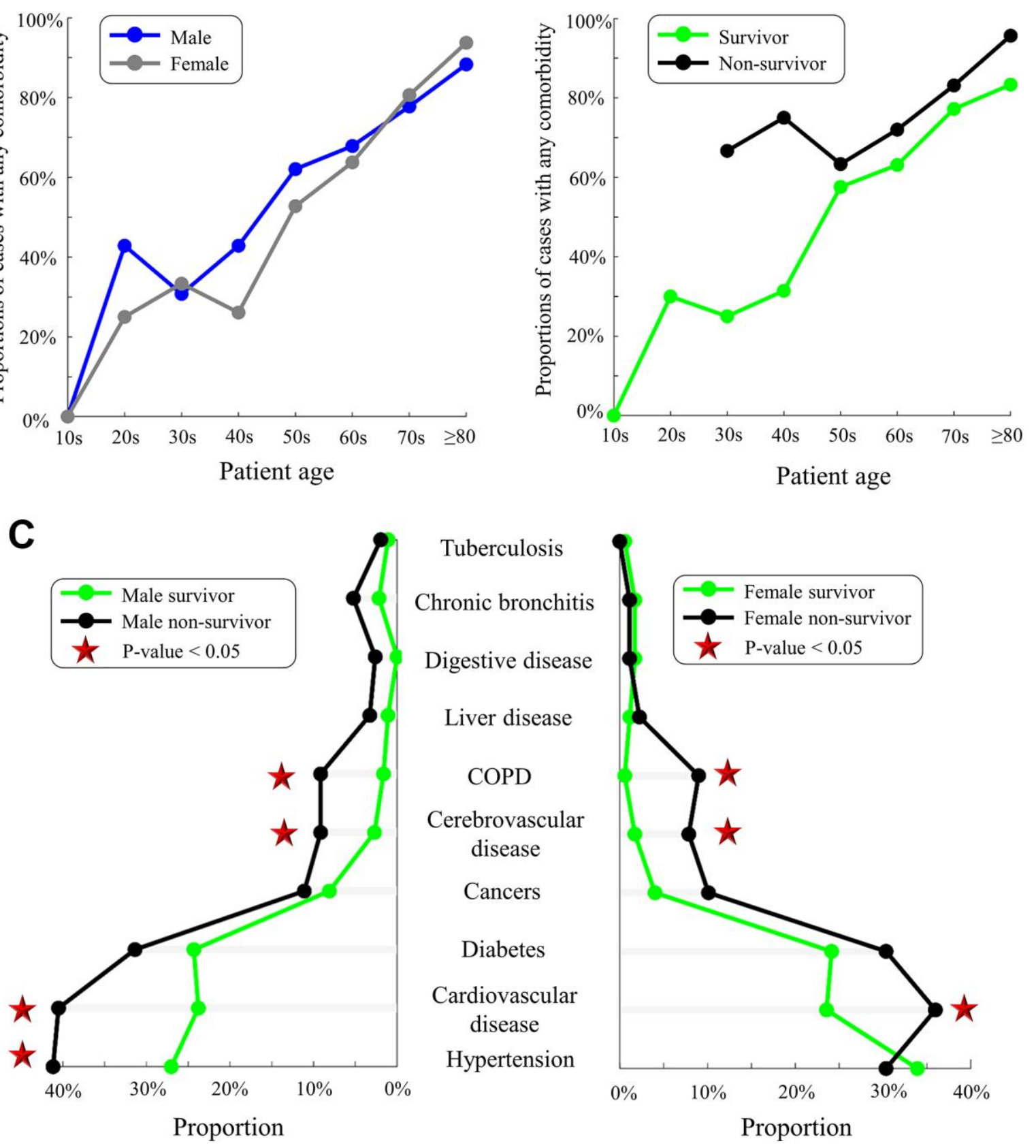

Figure 3. Pre-existing comorbidities in males/females and survivors/non-survivors. (A) Proportions of males (blue) and females (gray) with any comorbidity. (B) Proportions of survivors (green) and non-survivors (black) with any comorbidity. (C) Comorbidities in male survivors/non-survivors (left) and female survivors/non-survivors (right). Red stars indicate the significant difference in proportions between survivors and non-survivors ( $\mathrm{p}$-value<0.05). 
cerebrovascular disease (median: 14 versus 59 days, pvalue $<0.001$, Figure 6D) or COPD (median: 11 versus 59 days, p-value $<0.001$, Supplementary Figure 2B) also had a shorter survival time than patients without these comorbidities.
We next evaluated the length of hospital stay under preexisting conditions of age, gender, and comorbidities (Figure 6E). The length of hospital stay was shorter among non-survivors (median: 11, interquartile range (IQR): 7 to 21 days) than among survivors (median: 20,

A

A male patient with COVID-19

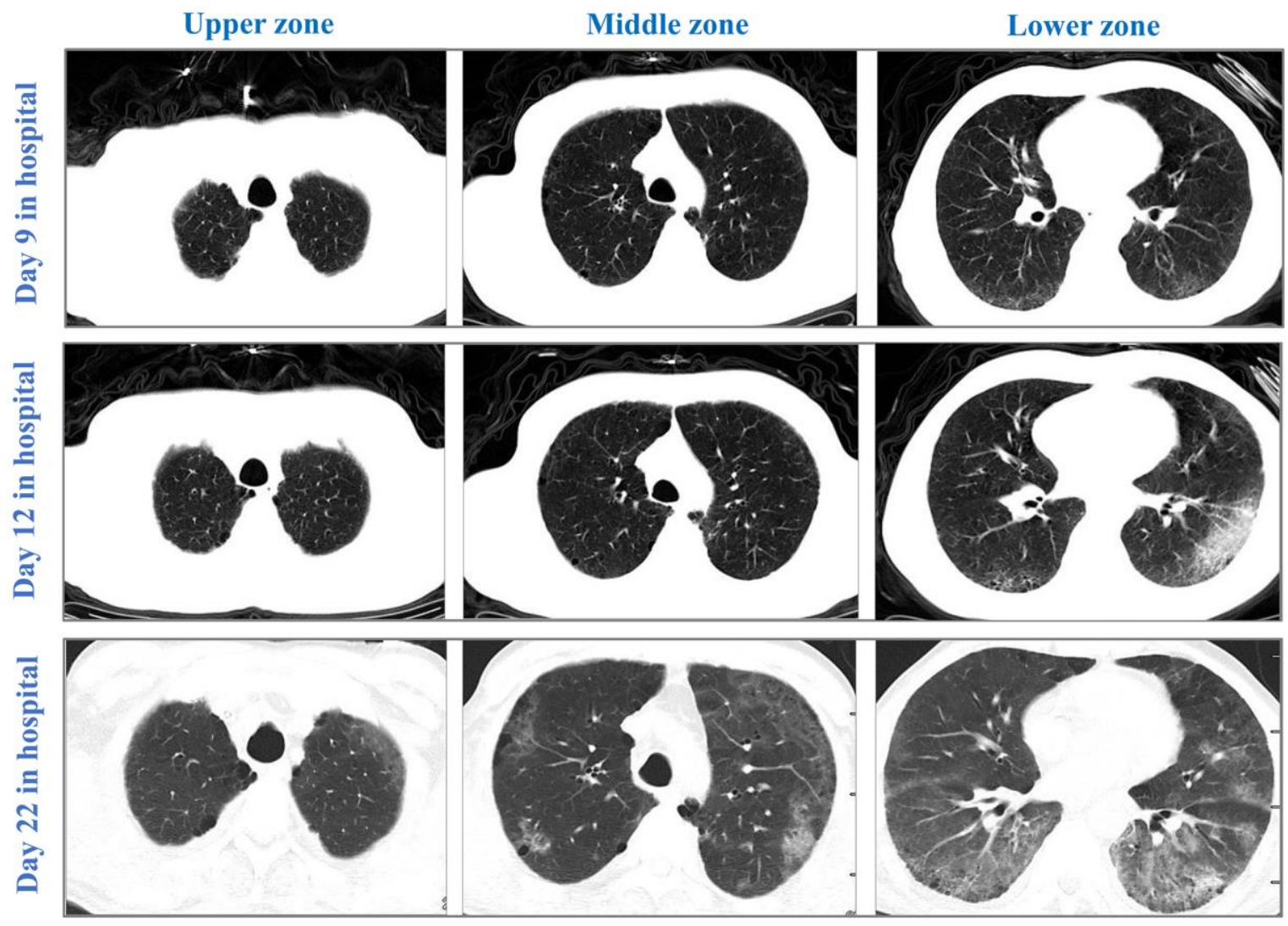

\section{B A normal male without COVID-19}

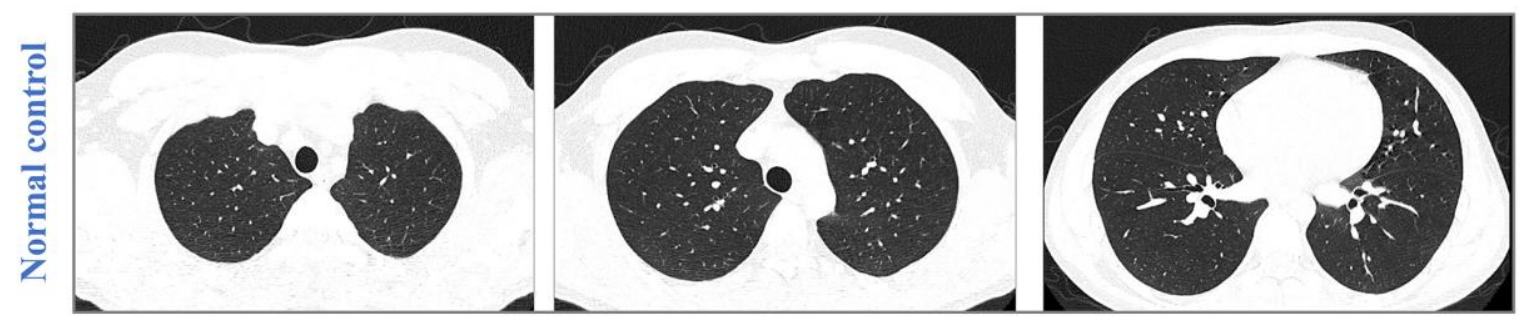

Figure 4. CT images from an elderly male with laboratory-confirmed COVID-19 (A) and a normal male without COVID-19 (B). CT images were illustrated in the upper zone (above the carina), the middle zone (below the carina up to the inferior pulmonary vein), and the lower zone (below the inferior pulmonary vein). After 9-day hospitalization, CT images showed minor ground-glass opacity (GGO) in subpleural areas of the lower left and right lobes in the COVID-19 male. After 12-day hospitalization, CT images showed progressing GGOs and newly-appeared reticulation. The vascular enlargement was observed in the lesion of the lower left lung. A small amount of bilateral pleural effusion was newly developed. After 22-day hospitalization, CT images showed progressing lesion with multiple newly-appeared GGO in both lungs, predominantly located in subpleural areas of lower lobes. Bronchiectasis of the anterior internal basal segment of the left lower lung was visible. Progressing bilateral pleural effusion was identified. The patient passed away after 24 days of hospitalization in The First Hospital of Changsha. 
Table 2. Clinical features of COVID-19 patients with the complete records of symptoms, comorbidities, clinical outcomes, and survival time.

\begin{tabular}{|c|c|c|c|c|}
\hline Characteristics & Total $(\mathrm{N}=399)$ & Survivors $(\mathrm{N}=\mathbf{2 4 2})$ & $\begin{array}{l}\text { Non-survivors } \\
\quad(\mathbf{N}=157)\end{array}$ & P-value \\
\hline Male & $215(54 \%)$ & $116(48 \%)$ & $99(63 \%)$ & 0.003 \\
\hline Age (years) & $66(58$ to 74$)$ & 65 (55 to 72$)$ & $70(63$ to 78$)$ & $1.2 \times 10^{-5}$ \\
\hline Chinese patients & $366(92 \%)$ & $224(93 \%)$ & $142(90 \%)$ & 0.45 \\
\hline \multicolumn{5}{|l|}{ Baseline symptoms } \\
\hline Any symptom & $392(98 \%)$ & $236(98 \%)$ & $156(99 \%)$ & 0.17 \\
\hline Fever & $326(82 \%)$ & $203(84 \%)$ & $123(78 \%)$ & 0.16 \\
\hline Cough & $256(64 \%)$ & $154(64 \%)$ & $102(65 \%)$ & 0.79 \\
\hline Shortness of breath & $149(37 \%)$ & $70(29 \%)$ & $79(50 \%)$ & $1.6 \times 10^{-5}$ \\
\hline Fatigue & $107(27 \%)$ & $65(27 \%)$ & $42(27 \%)$ & 0.98 \\
\hline Chills & $63(16 \%)$ & $38(16 \%)$ & $25(16 \%)$ & 0.95 \\
\hline Diarrhea & $59(15 \%)$ & $42(17 \%)$ & $17(11 \%)$ & 0.07 \\
\hline Myalgia & $58(14 \%)$ & $41(17 \%)$ & $17(11 \%)$ & 0.09 \\
\hline Appetite loss & $57(14 \%)$ & $39(16 \%)$ & $18(11 \%)$ & 0.19 \\
\hline Headache & $31(8 \%)$ & $20(8 \%)$ & $11(7 \%)$ & 0.65 \\
\hline Nausea & $29(7 \%)$ & $19(8 \%)$ & $10(6 \%)$ & 0.58 \\
\hline \multicolumn{5}{|l|}{ Comorbidity } \\
\hline Hypertension & $163(41 \%)$ & $94(39 \%)$ & $69(44 \%)$ & 0.31 \\
\hline Diabetes mellitus & $103(26 \%)$ & $56(23 \%)$ & $47(30 \%)$ & 0.13 \\
\hline Cardiovascular disease & $68(17 \%)$ & $31(13 \%)$ & $37(24 \%)$ & 0.005 \\
\hline Cerebrovascular disease & $25(6 \%)$ & $5(2 \%)$ & $20(13 \%)$ & $1.7 \times 10^{-5}$ \\
\hline Cancer & $20(5 \%)$ & $9(4 \%)$ & $11(7 \%)$ & 0.14 \\
\hline Chronic bronchitis & $16(4 \%)$ & $7(3 \%)$ & $9(6 \%)$ & 0.16 \\
\hline COPD \# & $11(3 \%)$ & $2(1 \%)$ & $9(6 \%)$ & 0.003 \\
\hline Chronic liver disease & $9(2 \%)$ & $2(1 \%)$ & $7(5 \%)$ & 0.017 \\
\hline Digestive disease & $8(2 \%)$ & $3(1 \%)$ & $5(3 \%)$ & 0.18 \\
\hline Tuberculosis & $6(2 \%)$ & $3(1 \%)$ & $3(2 \%)$ & 0.59 \\
\hline Any comorbidity & $258(65 \%)$ & $141(58 \%)$ & $117(75 \%)$ & $9.0 \times 10^{-4}$ \\
\hline 1 comorbidity & $136(34 \%)$ & $80(33 \%)$ & $56(36 \%)$ & \\
\hline 2 comorbidities & $78(20 \%)$ & $47(19 \%)$ & $31(20 \%)$ & 0.004 \\
\hline$\geq 3$ comorbidities & $44(11 \%)$ & $14(5 \%)$ & $30(12 \%)$ & \\
\hline \multicolumn{5}{|l|}{ Time to clinical outcome } \\
\hline Symptom onset to outcome & 29 (19 to 42$)$ & 38 (27 to 47$)$ & 17 (12 to 27$)$ & $<0.01$ \\
\hline Length of hospital stay & 17 (10 to 27$)$ & 20 (11 to 28$)$ & $11(7$ to 21$)$ & $2.2 \times 10^{-10}$ \\
\hline
\end{tabular}

\#: COPD: chronic obstructive pulmonary disease.

IQR: 11 to 28 days, p-value<0.01). The median time from hospital admission to discharge was significantly longer in elderly survivors (median: 23, interquartile range (IQR): 18.5 to 32 days) than in young survivors (median: 17, IQR: 10 to 23 days, p-value<0.001). Survivors with comorbidities had a longer period of hospital stay than survivors without comorbidities (median: 21 versus 15 days, p-value<0.001). For survivors, elderly males with comorbidities required 25 days (IQR: 18 to 35 days) of hospital stay, which was much longer than young females without comorbidities (median: 14, IQR: 9 to 19 days, p-value<0.001). For 
Table 3. Risk factors in the survival model of COVID-19 using Cox proportional hazards models.

\begin{tabular}{lcccc}
\hline & \multicolumn{2}{c}{ Univariate analysis } & Multivariate analysis \\
\cline { 2 - 4 } & HR $(\mathbf{9 5 \%}$ CI $)$ & P-value & HR (95\% CI) & P-value \\
\hline Male & $1.53(1.29$ to 1.80$)$ & 0.01 & $1.41(1.19$ to 1.67$)$ & 0.039 \\
Patient age* & $1.04(1.03$ to 1.05$)$ & $6.4 \times 10^{-8}$ & $1.03(1.02$ to 1.04$)$ & $3.0 \times 10^{-5}$ \\
Region \& & $0.52(0.39$ to 0.68$)$ & 0.06 & & \\
Signs or symptoms & & & \\
Any symptom & $2.65(0.97$ to 7.23$)$ & 0.33 & \\
Fever & $0.76(0.63$ to 0.93$)$ & 0.16 & \\
Cough & $0.89(0.75$ to 1.05$)$ & 0.49 & \\
Shortness of breath & $1.86(1.59$ to 2.18$)$ & $1.0 \times 10^{-4}$ & $1.74(1.47$ to 2.05$)$ & \\
Fatigue & $0.90(0.75$ to 1.08$)$ & 0.55 & \\
Myalgia & $0.64(0.49$ to 0.82$)$ & 0.08 & \\
Chills & $0.92(0.74$ to 1.14$)$ & 0.69 & \\
Diarrhea & $0.63(0.48$ to 0.81$)$ & 0.07 & \\
Headache & $0.81(0.59$ to 1.11$)$ & 0.49 & \\
Nausea & $0.78(0.56$ to 1.09$)$ & 0.46 & \\
Appetite loss & $0.64(0.50$ to 0.82$)$ & 0.08 & \\
Comorbidity & & & \\
Any comorbidity & $1.79(1.49$ to 2.15$)$ & 0.002 & \\
Hypertension & $1.23(1.05$ to 1.45$)$ & 0.19 & \\
Diabetes mellitus & $1.27(1.06$ to 1.51$)$ & 0.18 & \\
Cardiovascular disease & $1.74(1.44$ to 2.10$)$ & 0.004 & \\
Cerebrovascular disease & $4.11(3.23$ to 5.24$)$ & $5.1 \times 10^{-9}$ & $3.28(2.55$ to 4.23$)$ \\
Chronic liver disease & $1.90(1.29$ to 2.80$)$ & 0.09 & \\
Digestive disease & $1.93(1.23$ to 3.05$)$ & 0.15 & \\
Cancer & $1.50(1.10$ to 2.05$)$ & 0.20 & \\
Chronic bronchitis & $1.76(1.25$ to 2.48$)$ & 0.10 & \\
COPD & $3.45(2.44$ to 4.88$)$ & $3.6 \times 10^{-4}$ & $2.19 \times 10^{-6}$ \\
Tuberculosis & $1.28(0.71$ to 2.29$)$ & 0.68 & \\
\hline
\end{tabular}

* : Increase per year. \&: Patients in China versus Europe/North America.

non-survivors, the median time from hospital admission to death was 11.5 days (IQR: 7 to 22 days). Moreover, elderly non-survivors had a shorter length of hospital stay compared with young non-survivors (median: 10 versus 14 days, $p$-value $=0.003$ ). The length of hospital stay was shorter in elderly male non-survivors (median: 10, IQR: 6 to 18.5 days) than in young male nonsurvivors (median: 15, IQR: 9.5 to 27 days, pvalue $=0.003$ ). Overall, mortality-associated risk factors exert an impact on the hospital stay and survival time in COVID-19 patients.

\section{DISCUSSION}

To understand why some COVID-19 patients are more susceptible to fatal outcomes, we explored epidemiological and clinical records of survivors and non-survivors from China, European regions, and North America. Our study revealed three major findings. (i)
High mortality risk of COVID-19 was consistently found among elderly males from China, Europe, and North America. (ii) Risk factor and survival analyses revealed mortality-associated risk factors of age, male gender, shortness of breath, and chronic comorbidities such as cerebrovascular disease and COPD. (iii) Mortality-associated risk factors exert an impact on the survival time and hospital stays of elderly patients. To reduce mortality rates and hospital burden, we carried out a multi-country study on COVID-19-induced mortality, and the results support the early prevention and critical care of elderly males with specific comorbidities.

\section{Elderly adults with an increased risk of COVID-19}

In agreement with previous findings [2, 4, 10, 11], our survival analyses suggested that the mortality risk of COVID-19 increased with patient age (HR: 1.04 
Table 4. Mortality-associated factors in the original sample and the propensity score-matched samples.

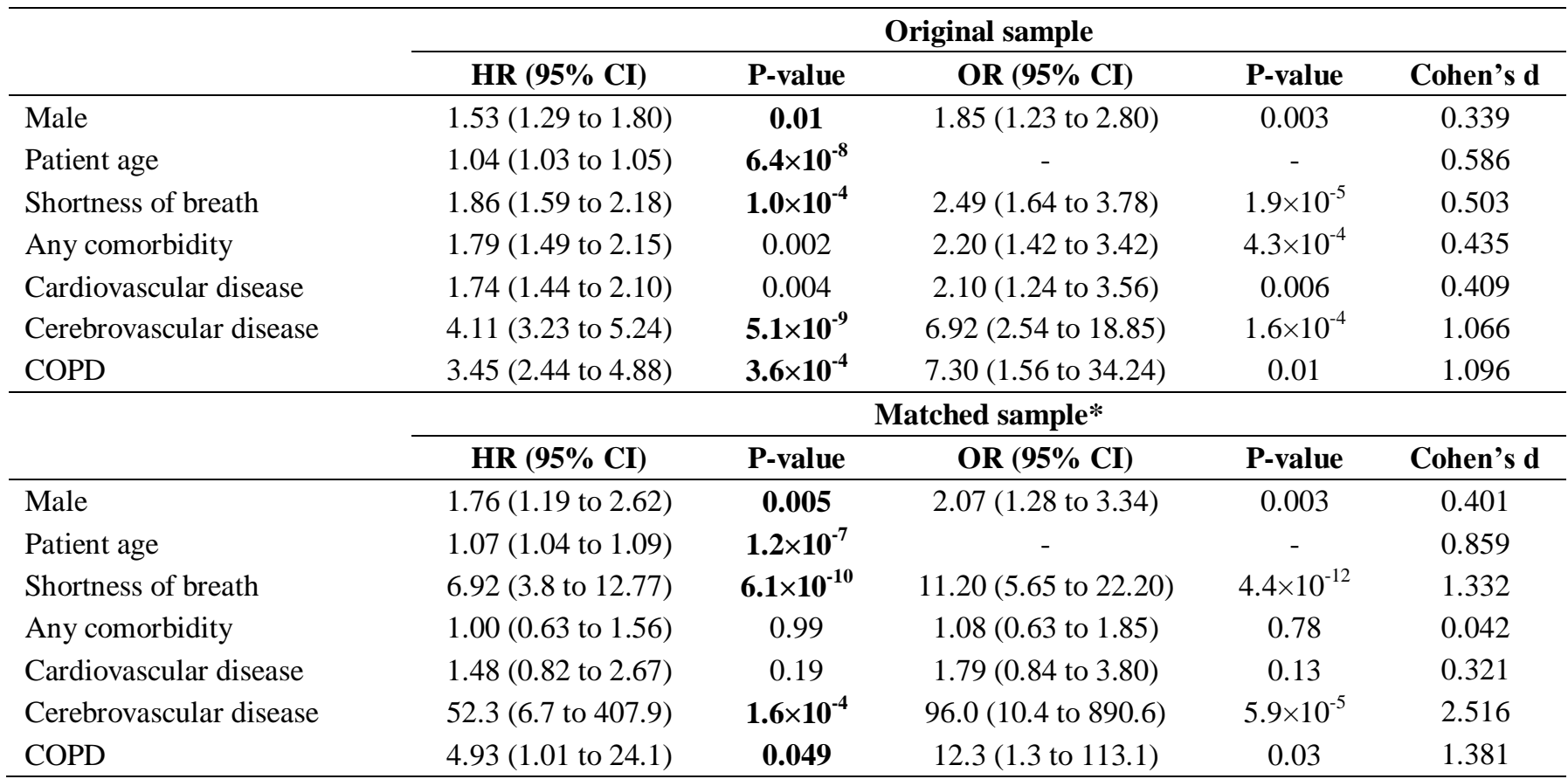

*: The propensity score-matched samples are described in Supplementary Table 3.1 to Supplementary Table 3.7.

-: The OR of patient age was not measured because patient age was a continuous variable.

increase per year), and most deaths were observed in elderly adults, especially those $\geq 70$ years $(>50 \%$ of nonsurvivors). Of interest, the high mortality risk of elderly adults was consistently observed in China, European regions, and North America (Figure 2). Indeed, similar findings have been consistently reported by singlecountry studies of COVID-19 patients in many countries such as America [12], Belgium [13], Canada [14], France [15], Germany [16], Italy [17], Mexico [18], Poland [19], Romania [20], Russia [21], Spain [22], and the United Kingdom [23]. Of note, age, gender, and chronic comorbidities are key factors that determine hospitalization rather than outpatient care [10]. For instance, elderly survivors required a longer length of hospital stay than non-survivors (Figure 6). The elderly required longer hospital stays than young adults, probably because close monitoring of their recovery requires more time in the hospital. Similar to our findings, a small-cohort study of 17 non-survivors reported a short time (median: 11.5 days) from symptom onset to death in patients $\geq 70$ years [24]. Overall, our study and literature findings support the early prevention of COVID-19 in elderly adults due to their high risk.

Why are elderly adults more vulnerable to COVID-19? Although the exact mechanisms remain unclear, several hypotheses have been proposed [25]. First, compared with young patients, elderly adults with compromised immunity might have slower, less coordinated, and less efficient immune responses to COVID-19 [26, 27]. Additionally, the innate and adaptive systems are possibly suboptimal in elderly patients. For instance, $\mathrm{T}$ and $\mathrm{B}$ lymphocytes are critical components of adaptive immune responses to emerging infections, but elderly patients may experience age-related dysfunction with a decreased production of $\mathrm{T}$ and $\mathrm{B}$ lymphocytes [28]. Second, elderly adults may have an increased risk of exposure to COVID-19, problems with access to health services, and less opportunity to receive respiratory support in resource-limited settings [29]. Third, elderly adults usually have comorbid conditions such as acute respiratory distress syndrome, which may diminish their recovery from COVID-19 [30].

\section{Elderly males with a high mortality risk}

In agreement with previous studies [12-23], our study showed gender disparities in that COVID-19 killed more males than females especially in elderly populations (Figure 2), and our survival analyses revealed age and male gender as risk factors to be associated with mortality (Table 3 ). Of note, the fatality rate was higher in males $(2.84 \%, 653 / 22981)$ than females $(1.71 \%, 370 / 21691)$ in mainland China [31]. In Italy, males accounted for $82 \%$ of 1591 critically ill patients with ICU admission [32]. During the screening 


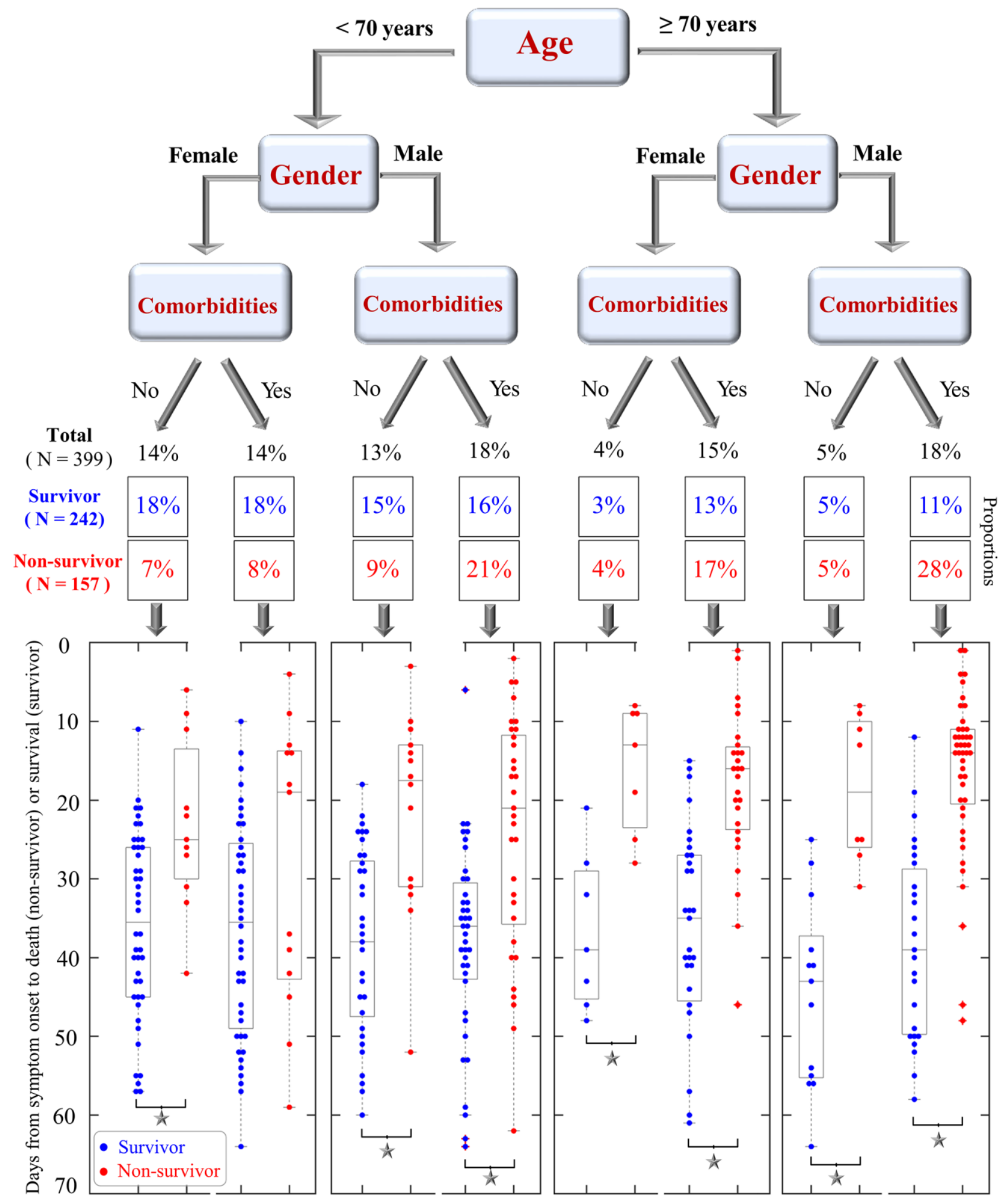

Figure 5. A tree model that shows the proportions of COVID-19 survivors and non-survivors based on three conditions: patient age (<70 or $\geq 70$ years), gender (female, male), and pre-existing comorbidities (yes or no). Scatter plots at the bottom visualize the days from symptom onset to clinical outcomes (death for non-survivors and survival for survivors). Blue and red dots are shown for survivors and non-survivors, respectively. Significant differences in survival time between survivors and non-survivors are indicated by black asterisks. 
A

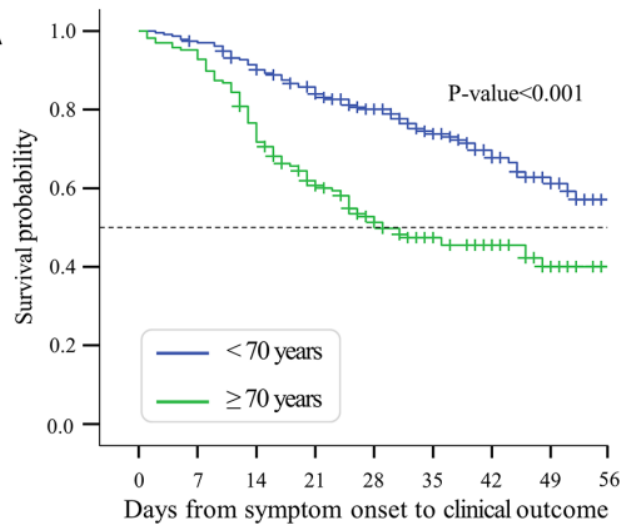

C

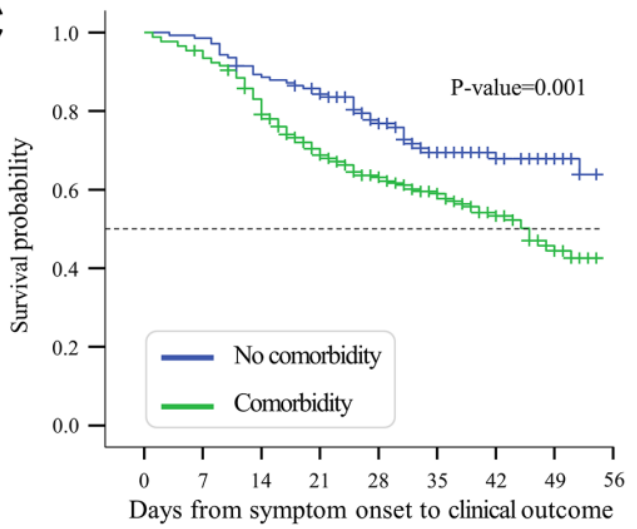

B

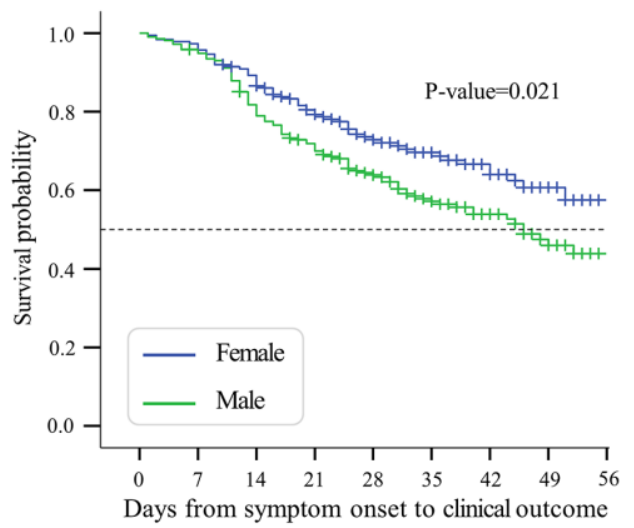

D

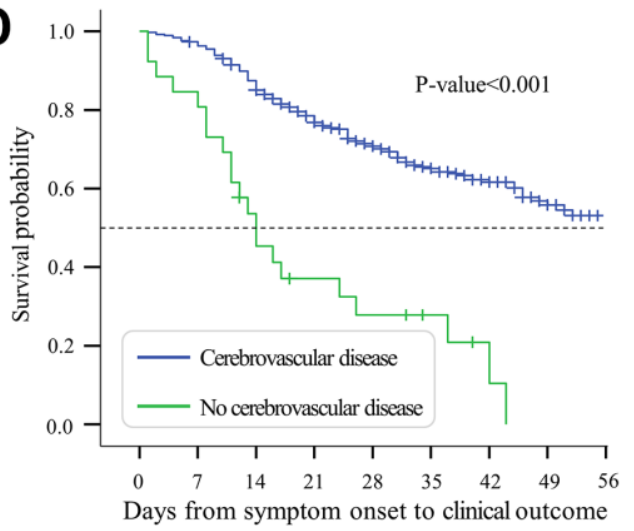

E
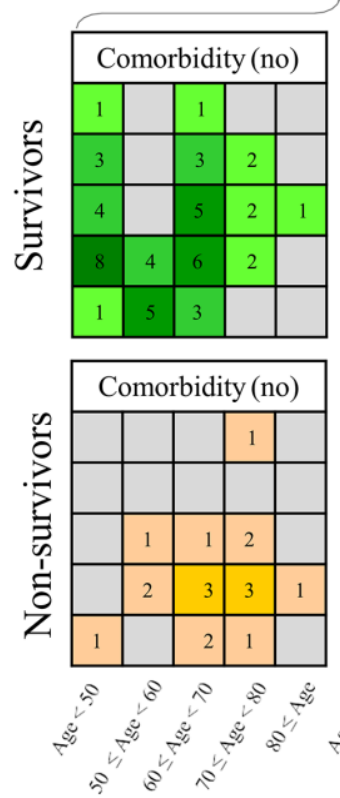

Females
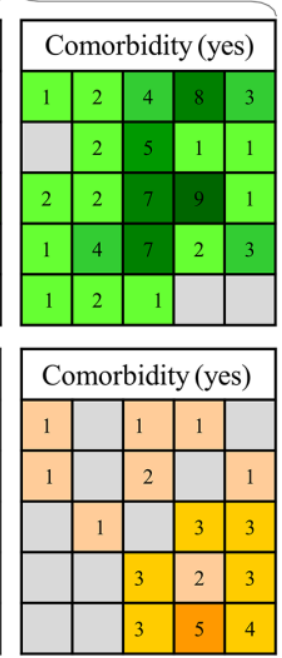

$\therefore 8080$

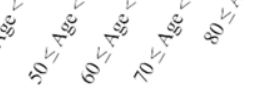

Patient ages

Males
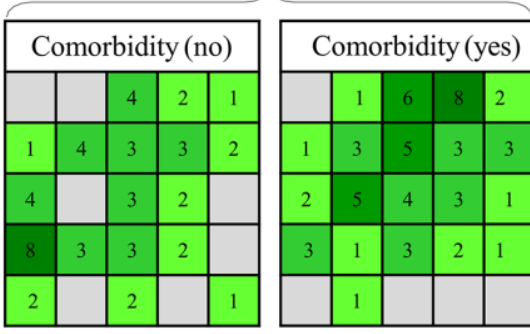

Hospital stay

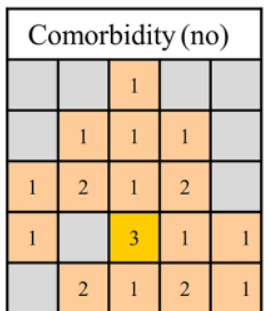

$\therefore \& 0 \%$

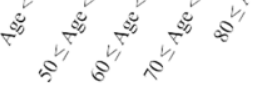

$8^{2,}$

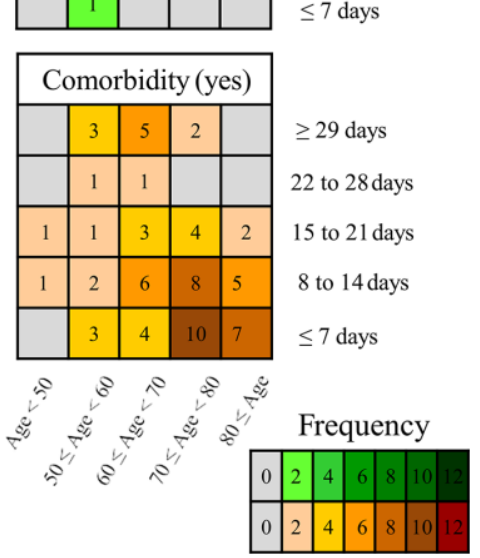

Figure 6. Kaplan-Meier curves and plots of hospital stays. (A) Survival probability of elderly patients $\geq 70$ years versus young patients $<70$ years. (B) Survival probability of males versus females with COVID-19. (C) Survival probability of patients with versus without any comorbidity. (D) Survival probability of patients with versus without cerebrovascular disease. (E) Length of hospital stays under the conditions of patient age, gender, and comorbidities. Colored cells indicate the number of observed cases regarding the length of hospital stay. Days from symptom onset to clinical outcomes are shown in Supplementary Figure 3. 
of COVID-19 in Iceland, a higher proportion of positive cases was observed in males $(1.1 \%, 46 / 5004)$ than females $(0.7 \%, 41 / 5793)$ [33]. Accumulated evidence shows that more males than females are dying of COVID-19 across more than 100 countries according to sex-disaggregated data from Global Health 50/50 (http://globalhealth5050.org/covid19/).

Why does COVID-19 kill more males than females? Although the exact mechanisms remain unknown, several hypotheses have been proposed to explain gender disparities. (i) The $\mathrm{X}$ chromosome encodes the human receptor angiotensin-converting enzyme 2 (ACE2, gene ID: 59272), which is the human receptor mediating SARS-CoV-2 entry into human cells. Expression of ACE2 might vary in different populations due to genetic differences [34]. (ii) Males and females have different immune responses to COVID-19 due to the sex chromosomes (XY in males, $\mathrm{XX}$ in females), sex hormones (androgens, estrogens), and regulatory genes associated with the immune system [35]. Since the $X$ chromosome encodes the largest number of immunerelated genes in the human genome, females carrying two copies of the $\mathrm{X}$ chromosome may have immunological advantages regarding resistance to viral pathogens, but they also develop more autoimmune diseases [36, 37]. (iii) Different socioeconomic and lifestyle behaviors such as smoking, alcohol consumption, and personal hygiene may also play a role in gender differences in susceptibility to COVID-19 [38].

\section{Comorbidities increase the risk of COVID-19}

In agreement with previous studies [39-41], we observed a higher proportion of comorbidities (e.g. cerebrovascular disease, cardiovascular disease, COPD) in non-survivors than in survivors (Table 2). Furthermore, pre-existing comorbidities may reduce the survival time in non-survivors and increase the length of hospital stay of survivors (Figure 6). Similar to our results in Table 2, severely ill patients had more comorbidities, including hypertension (56\%), heart disease $(21 \%)$, diabetes $(18 \%)$, cerebrovascular disease (12\%), and cancer (7\%) [42]. Comorbidities were also observed in $94 \%$ of 5700 COVID-19 patients hospitalized in New York [43]. Our study showed slightly higher (but insignificant) proportions of comorbidities such as diabetes mellitus, cardiovascular disease, cerebrovascular disease, chronic bronchitis, and COPD in males than females (Supplementary Table 1). Multisystem organ dysfunction in males might be associated with a high rate of mortality [32].

What are the impacts of comorbidities on the morbidity and mortality of COVID-19? Although the possible mechanisms are still under investigation, answers likely depend on the type of comorbidity. First, our analyses revealed that the comorbidities of cerebrovascular disease and COPD are time-dependent factors associated with a fatal outcome of COVID-19 (Tables 3, 4). Of interest, cerebrovascular disease was also recognized as a risk factor in a retrospective study of 50 non-survivors and 1540 survivors [40]. Furthermore, a meta-analysis reported an approximately 2.5 -fold increase in the odds of severe disease in the presence of cerebrovascular disease [44]. Pre-existing COPD was previously confirmed as a key factor that contributes to the worse progression and outcome of COVID-19 [45]. Due to SARS-CoV-2 invasion of the central nervous system, severely ill patients are more likely to develop neurologic manifestations, especially acute cerebrovascular disease [46]. Second, possible crosstalk between diabetes and COVID-19 might be involved with ACE2 and dipeptidyl peptidase-4, two important human proteins in the biological pathways of both diseases [47, 48]. Third, cardiovascular disease involves an increased risk of inhospital death in COVID-19, which might be mediated by ACE2-dependent myocardial infection [49] or the high inflammatory burden that can induce vascular inflammation, myocarditis, and cardiac arrhythmias [50]. Fourth, patients with lung cancer, hematological cancer, or cancers in metastatic stages have higher rates of severe outcomes than patients without cancer [51]. Overall, comorbidities are likely associated with the severity of COVID-19 [39, 41].

\section{Limitations}

First, we initially intended to collect all available online records of COVID-19 cases worldwide, but detailed medical records of individual patients were mostly lacking probably because the privacy of patient data is protected and detailed records are often not published in an emergent outbreak. Nevertheless, our major findings of elderly males at high risk for COVID-19 have been consistently confirmed by single-country studies [1223]. Future multi-country studies are yet needed to retrieve complete records worldwide and characterize COVID-19 mortality from a global perspective. Second, our retrospective study describes potential associations of risk factors with mortality, but crosstalk between human and viral proteins in the lifecycle of SARS-CoV2 needs to be clarified by future studies. Third, the role of treatments in fatal outcomes of COVID-19 was not analyzed because multiple treatments (e.g. antiviral/antibiotic/antifungal therapies, ventilation, oxygen therapy) are often administered. The possible role of prevention strategies in reducing mortality was not analyzed due to limited data. Moreover, controlled cohorts were not available for our study. Randomized controlled cohorts are thus needed to assess the use of potential treatments in elderly patients with COVID-19. 


\section{CONCLUSIONS}

Given the rapid spread of COVID-19 worldwide, a better understanding of high-risk populations is important for decision making in the treatment and prevention of the disease. The clinical features of nonsurvivors inside and outside Wuhan are similar [28], supporting universal strategies to handle COVID-19 across different cities and countries. As of today, there is no cure to eliminate COVID-19 so that prevention strategies are critical for reducing COVID-19 infections. In addition to prevention measures (e.g. face masks, good hygiene, social distancing, contract tracing, travel restrictions, lockdowns, and quarantine) that limit the spread of COVID-19, intensive surveillance and hospital/outpatient caregiving should be adapted for elderly patients with COVID-19. Current guidelines should also pay more attention to high-risk populations of elderly patients with COVID-19-associated comorbidities, complications, and polypharmacy.

\section{MATERIALS AND METHODS}

\section{Data collection of COVID-19 patients}

Our workflow, as shown in Figure 1, was conducted to collect clinical records for COVID-19 patients in China, North America, and European regions. First, we collected epidemiological and clinical records of COVID-19 patients who were hospitalized before May $1^{\text {st }}, 2020$, in the Sino-French New-City Tongji Hospital in Wuhan. At hospital admission, all patients were diagnosed with COVID-19. Nasal and pharyngeal swab specimens were collected to assess the presence of SARS-CoV-2 using real-time RT-PCR tests according to WHO interim guidelines. All survivors, who fulfilled discharge criteria, were discharged for 14-day home quarantine based on the New Coronavirus Diagnosis and Treatment Guidelines in China (Supplementary Method 1). A total of 232 survivors and 60 non-survivors were included in our dataset. Second, to increase the sample size, we extracted clinical records for all COVID-19 non-survivors from The First Hospital of Changsha in China. Third, we attempted to extract online records for COVID-19 individuals in China, European regions, and North America. Online collections were conducted using a four-fold procedure. (i) We searched online records of COVID-19 patients in China, 15 countries in North America, and 43 countries in Europe (Supplementary Table 4) where a large number of COVID-19 patients were reported between January and April 2020. (ii) We searched records of COVID-19 individuals in the scientific literature, official media/conferences, hospital websites, government (state, provincial, national) websites, and Centers for Disease Control and Prevention. Only individual cases with epidemiological and clinical information were retrieved, while clinical studies or meta-analyses that shared no individual records were not considered. (iii) We used keywords such as: "COVID", "SARS-CoV-2", "2019-nCoV", "new coronavirus", "mortality", "death" and "survivor" to screen online data. (v) Duplicates were removed and all records were cross-checked by at least two investigators.

The data extraction (as described above) retrieved a total of 1267 patients, including 666 survivors and 601 nonsurvivors. Because remdesivir and dexamethasone significantly reduce COVID-19 mortality [8, 9], our analyses excluded patients who received remdesivir $(\mathrm{N}=8)$ and/or dexamethasone $(\mathrm{N}=73)$. Moreover, 42 patients were excluded because they had no treatment records and were hospitalized after May 1, 2020. Of 59 countries in our search list, 35 had fewer than five extracted records in our dataset, which is unlikely to be representative; therefore, 73 cases from these countries were excluded. Supplementary Table 4 summarizes the country list and case numbers in 59 countries. For data transparency, the compiled online resources of 981 COVID-19 patients are shared in Supplementary Data 1.

A total of 568 survivors and 507 non-survivors with basic information regarding age, gender, country, and clinical outcomes were included in our age-gender analysis (Table 1 and Figure 2). Additional information on baseline symptoms and comorbidities was also recorded in a subset of 359 survivors and 239 nonsurvivors, which was used for comorbidity analyses (Figure 3). Survival time, as defined by the days from symptom onset of clinical outcomes, was identified in a subset of 242 survivors and 157 non-survivors and, subsequently used for risk-factor analyses and survival analyses (Tables 2-4 and Figures 5, 6). Figure 1 summarizes our workflow and data structures.

\section{Data management}

Our datasets included demographic features (age, gender, cities), signs and symptoms, pre-existing comorbidities, complications before death, and other available data (e.g. symptom onset date, admission date, computerized tomography data) for COVID-19 survivors and nonsurvivors. Symptoms, comorbidities, and complications were treated as categorical variables (yes or no). Clinical outcomes were defined by the status of death (nonsurvivors) or hospital discharge after the clearance of COVID-19 (survivors). For non-survivors, the survival time was defined by days from symptom onset to the date of death. Since death was not observed before hospital discharge, survivors were treated as censored data in which the observation time was defined by days from symptom onset to hospital discharge. 


\section{Statistical analysis}

In comparisons of COVID-19 survivors and nonsurvivors, continuous variables were analyzed using Mann-Whitney U tests, while categorical variables were analyzed using $\chi^{2}$ tests or Fisher's exact tests as appropriate. Survival analyses were performed using Cox proportional hazards models. Hazard ratios with the $95 \%$ confidence interval were assessed to reveal the effects of risk factors on survival-time outcomes: either death for non-survivors or hospital discharge for survivors. Kaplan-Meier curves were built to show survival time among patient groups (e.g. elderly versus young patients), and significant differences were examined by log-rank tests. A common approach called pairwise deletion was applied to handle missing data. Since no random sampling was conducted, all statistical analyses were descriptive. To reduce the confounding effect in this nonrandomized study, the propensity-score matching method in SPSS V26.0 was applied with default settings (e.g. one-to-one matching, matching tolerance: 0.02) to assess whether any observed confounding was adequately reduced. The effect size of risk factors was estimated by Cohen's d [52]. In all significance tests, two-tailed tests were performed and P-values $<0.05$ were considered statistically significant.

\section{Ethics declarations}

This retrospective study was performed in accordance with the Helsinki Declaration and was approved by the Ethics Committees of The Second Xiangya Hospital, Central South University (ID: LYF2020060), and The First Hospital of Changsha (ID: KX2020002). Written informed consent was waived for analyzing archived records in this retrospective study.

\section{Availability of clinical data}

Supplementary Data 1 shares online records of COVID19 patients.

\section{AUTHOR CONTRIBUTIONS}

GL, YL, and YW performed statistical analyses and drafted the manuscript; YL, XJ, MM, and YW performed data acquisition of non-survivors; MZ, JL, and PJ performed data acquisition of survivors; ZZ, YX, YH, JL, and GG conducted clinical practice and data interpretation; YTH, NRF, and EDC contributed with discussions and writing of the manuscript; GL and MZ supervised the study, obtained funding, and revised the manuscript. All authors contributed to the final article.

\section{ACKNOWLEDGMENTS}

The authors acknowledge the study investigators, coordinators, nurses, and patients for their contributions in this study.

\section{CONFLICTS OF INTEREST}

The authors disclose no conflicts of interest.

\section{FUNDING}

This work was supported by the National Nature Science Foundation of China (31871324, 81730064, 31571368), Natural Science Foundation of Hunan Province (2018JJ3713, 2018JJ2452), Hunan Youth Elite Project (2018RS3006), National Science and Technology Major Project (2018ZX10715004), Emergency Projects against the Novel Coronavirus in Hunan Province (2020SK3013, 2020SK3014), and a Sir Henry Dale Fellowship (204311/Z/16/Z). The funders had no role in study design, data collection, data analysis, data interpretation, or writing of the report.

\section{REFERENCES}

1. Li G, De Clercq E. Therapeutic options for the 2019 novel coronavirus (2019-nCoV). Nat Rev Drug Discov. 2020; 19:149-50.

https://doi.org/10.1038/d41573-020-00016-0 PMID:32127666

2. Yang $X, Y u Y, X u$ J, Shu H, Xia J, Liu H, Wu Y, Zhang L, Yu $Z$, Fang $M, Y u T$, Wang $Y$, Pan $S$, et al. Clinical course and outcomes of critically ill patients with SARS-CoV-2 pneumonia in Wuhan, China: a single-centered, retrospective, observational study. Lancet Respir Med. 2020; 8:475-81.

https://doi.org/10.1016/S2213-2600(20)30079-5 PMID: 32105632

3. Wang Y, Lu X, Li Y, Chen H, Chen T, Su N, Huang F, Zhou J, Zhang B, Yan F, Wang J. Clinical course and outcomes of 344 intensive care patients with COVID-19. Am J Respir Crit Care Med. 2020; 201:1430-34. https://doi.org/10.1164/rccm.202003-0736LE PMID: 32267160

4. Li X, Xu S, Yu M, Wang K, Tao Y, Zhou Y, Shi J, Zhou M, Wu B, Yang Z, Zhang C, Yue J, Zhang Z, et al. Risk factors for severity and mortality in adult COVID-19 inpatients in Wuhan. J Allergy Clin Immunol. 2020; 146:110-18.

https://doi.org/10.1016/j.jaci.2020.04.006 PMID: $\underline{32294485}$

5. Zhou F, Yu T, Du R, Fan G, Liu Y, Liu Z, Xiang J, Wang Y, Song B, Gu X, Guan L, Wei Y, Li H, et al. Clinical course 
and risk factors for mortality of adult inpatients with COVID-19 in Wuhan, China: a retrospective cohort study. Lancet. 2020; 395:1054-62.

https://doi.org/10.1016/S0140-6736(20)30566-3

PMID: 32171076

6. Wu C, Chen X, Cai Y, Xia J, Zhou X, Xu S, Huang H, Zhang L, Zhou X, Du C, Zhang Y, Song J, Wang S, et al. Risk Factors Associated With Acute Respiratory Distress Syndrome and Death in Patients With Coronavirus Disease 2019 Pneumonia in Wuhan, China. JAMA Intern Med. 2020; 180:934-43.

https://doi.org/10.1001/jamainternmed.2020.0994 PMID:32167524

7. Du RH, Liang LR, Yang CQ, Wang $W$, Cao TZ, Li M, Guo GY, Du J, Zheng CL, Zhu Q, Hu M, Li XY, Peng P, Shi HZ. Predictors of mortality for patients with COVID-19 pneumonia caused by SARS-CoV-2: a prospective cohort study. Eur Respir J. 2020; 55:2000524.

https://doi.org/10.1183/13993003.00524-2020 PMID:32269088

8. Olalla J. Remdesivir for the treatment of covid-19 preliminary report. N Engl J Med. 2020; 383:993-94. https://doi.org/10.1056/NEJMc2022236 PMID: $\underline{32649077}$

9. RECOVERY Collaborative Group, Horby P, Lim WS, Emberson JR, Mafham M, Bell JL, Linsell L, Staplin N, Brightling C, Ustianowski A, Elmahi E, Prudon B, Green C, et al. Dexamethasone in Hospitalized Patients with Covid-19 - Preliminary Report. N Engl J Med. 2020.

https://doi.org/10.1056/NEJMoa2021436 PMID: $\underline{32678530}$

10. Petrilli CM, Jones SA, Yang J, Rajagopalan H, O’Donnell L, Chernyak Y, Tobin KA, Cerfolio RJ, Francois F, Horwitz LI. Factors associated with hospital admission and critical illness among 5279 people with coronavirus disease 2019 in New York city: prospective cohort study. BMJ. 2020; 369:m1966.

https://doi.org/10.1136/bmj.m1966

PMID:32444366

11. Munayco C, Chowell G, Tariq A, Undurraga EA, Mizumoto K. Risk of death by age and gender from CoVID-19 in Peru, march-may, 2020. Aging (Albany NY). 2020; 12:13869-81.

https://doi.org/10.18632/aging.103687

PMID:32692724

12. Harrison SL, Fazio-Eynullayeva E, Lane DA, Underhill P, Lip GY. Comorbidities associated with mortality in 31,461 adults with COVID-19 in the United States: a federated electronic medical record analysis. PLoS Med. 2020; 17:e1003321. https://doi.org/10.1371/journal.pmed.1003321 PMID:32911500
13. Catteau L, Dauby N, Montourcy M, Bottieau E, Hautekiet J, Goetghebeur E, van lerssel S, Duysburgh E, Van Oyen H, Wyndham-Thomas C, Van Beckhoven D, and Belgian Collaborative Group on COVID-19 Hospital Surveillance. Low-dose hydroxychloroquine therapy and mortality in hospitalised patients with COVID-19: a observational study of 8075 participants. Int J Antimicrob Agents. 2020; 56:106144.

https://doi.org/10.1016/j.ijantimicag.2020.106144 PMID:32853673

14. Stall NM, Wu W, Lapointe-Shaw L, Fisman DN, Giannakeas V, Hillmer MP, Rochon PA. Sex- and agespecific differences in COVID-19 testing, cases, and outcomes: a population-wide study in Ontario, Canada. J Am Geriatr Soc. 2020; 68:2188-91. https://doi.org/10.1111/igs.16761 PMID:32743827

15. Boëlle PY, Delory T, Maynadier X, Janssen C, Piarroux R, Pichenot $M$, Lemaire $X$, Baclet $N$, Weyrich $P$, Melliez $H$, Meybeck A, Lanoix JP, Robineau O. Trajectories of hospitalization in COVID-19 patients: an observational study in France. J Clin Med. 2020; 9:3148.

https://doi.org/10.3390/jcm9103148

PMID:33003375

16. Karagiannidis C, Mostert C, Hentschker C, Voshaar T, Malzahn J, Schillinger G, Klauber J, Janssens U, Marx G, Weber-Carstens S, Kluge S, Pfeifer M, Grabenhenrich L, et al. Case characteristics, resource use, and outcomes of 10021 patients with COVID-19 admitted to 920 German hospitals: an observational study. Lancet Respir Med. 2020; 8:853-62. https://doi.org/10.1016/S2213-2600(20)30316-7 PMID: 32735842

17. Poletti P, Tirani M, Cereda D, Trentini F, Guzzetta G, Marziano V, Buoro S, Riboli S, Crottogini L, Piccarreta R, Piatti A, Grasselli G, Melegaro A, et al. Age-specific SARS-CoV-2 infection fatality ratio and associated risk factors, Italy, February to April 2020. Euro Surveill. 2020; 25:2001383.

https://doi.org/10.2807/1560-7917.ES.2020.25.31. 2001383 PMID:32762797

18. Carrillo-Vega MF, Salinas-Escudero G, García-Peña C, Gutiérrez-Robledo LM, Parra-Rodríguez L. Early estimation of the risk factors for hospitalization and mortality by COVID-19 in Mexico. PLoS One. 2020; 15:e0238905.

https://doi.org/10.1371/journal.pone.0238905 PMID:32915872

19. Raciborski F, Pinkas J, Jankowski M, Sierpiński R, Zgliczyński WS, Szumowski $Ł$, Rakocy K, Wierzba W, Gujski M. Dynamics of the coronavirus disease 2019 outbreak in Poland: an epidemiological analysis of the first 2 months of the epidemic. Pol Arch Intern Med. 2020; 130:615-21. 
https://doi.org/10.20452/pamw.15430

PMID:32520475

20. Barbu MG, Thompson RJ, Thompson DC, Cretoiu D, Suciu N. The impact of SARS-CoV-2 on the most common comorbidities-A retrospective study on 814 COVID-19 deaths in Romania. Front Med (Lausanne). 2020; 7:567199.

https://doi.org/10.3389/fmed.2020.567199

PMID:33015111

21. Munblit D, Nekliudov NA, Bugaeva $P$, Blyuss $O$, Kislova M, Listovskaya E, Gamirova A, Shikhaleva A, Belyaev V, Timashev P, Warner JO, Comberiati P, Apfelbacher C, et al. StopCOVID cohort: an observational study of 3,480 patients admitted to the sechenov university hospital network in Moscow city for suspected COVID19 infection. Clin Infect Dis. 2020. [Epub ahead of print].

https://doi.org/10.1093/cid/ciaa1535 PMID:33035307

22. Borobia AM, Carcas AJ, Arnalich F, Álvarez-Sala R, Monserrat-Villatoro J, Quintana M, Figueira JC, Torres Santos-Olmo RM, García-Rodríguez J, Martín-Vega A, Buño A, Ramírez E, Martínez-Alés G, et al. A cohort of patients with COVID-19 in a major teaching hospital in Europe. J Clin Med. 2020; 9:1733. https://doi.org/10.3390/icm9061733 PMID:32512688

23. Docherty $A B$, Harrison $E M$, Green $C A$, Hardwick $H E$, Pius R, Norman L, Holden KA, Read JM, Dondelinger F, Carson G, Merson L, Lee J, Plotkin D, et al, and ISARIC4C investigators. Features of 20133 UK patients in hospital with covid-19 using the ISARIC WHO clinical characterisation protocol: prospective observational cohort study. BMJ. 2020; 369:m1985.

https://doi.org/10.1136/bmj.m1985 PMID:32444460

24. Wang W, Tang J, Wei F. Updated understanding of the outbreak of 2019 novel coronavirus (2019-nCoV) in Wuhan, China. J Med Virol. 2020; 92:441-47. https://doi.org/10.1002/imv.25689 PMID:31994742

25. Mueller AL, McNamara MS, Sinclair DA. Why does COVID-19 disproportionately affect older people? Aging (Albany NY). 2020; 12:9959-81.

https://doi.org/10.18632/aging.103344

PMID:32470948

26. Nikolich-Zugich J, Knox KS, Rios CT, Natt $B$, Bhattacharya D, Fain MJ. SARS-CoV-2 and COVID-19 in older adults: what we may expect regarding pathogenesis, immune responses, and outcomes. Geroscience. 2020; 42:505-14. https://doi.org/10.1007/s11357-020-00186-0 PMID: $\underline{32274617}$

27. Jiang C, Wang Y, Hu M, Wen L, Wen C, Wang Y, Zhu W, Tai S, Jiang Z, Xiao K, Faria NR, De Clercq E, Xu J, Li G. Antibody seroconversion in asymptomatic and symptomatic patients infected with severe acute respiratory syndrome coronavirus 2 (SARS-CoV-2). Clin Transl Immunology. 2020; 9:e1182.

https://doi.org/10.1002/cti2.1182 PMID:33005417

28. Zhou Z, Zhang $M$, Wang $Y$, Zheng $F$, Huang $Y$, Huang $K$, Yu Q, Cai C, Chen D, Tian Y, Lei J, Xiao X, Clercq E, et al. Clinical characteristics of older and younger patients infected with SARS-CoV-2. Aging (Albany NY). 2020; 12:11296-305.

https://doi.org/10.18632/aging.103535

PMID: $\underline{32575073}$

29. Lloyd-Sherlock P, Ebrahim S, Geffen L, McKee M. Bearing the brunt of covid-19: older people in low and middle income Countries. BMJ. 2020; 368:m1052. https://doi.org/10.1136/bmj.m1052 PMID:32169830

30. Deng Y, Liu W, Liu K, Fang YY, Shang J, Zhou L, Wang K, Leng $F$, Wei S, Chen L, Liu HG. Clinical characteristics of fatal and recovered cases of coronavirus disease 2019 in Wuhan, China: a retrospective study. Chin Med J (Engl). 2020; 133:1261-67. https://doi.org/10.1097/CM9.0000000000000824 PMID:32209890

31. Epidemiology Working Group for NCIP Epidemic Response, Chinese Center for Disease Control and Prevention. [The epidemiological characteristics of an outbreak of 2019 novel coronavirus diseases (COVID19) in China]. Zhonghua Liu Xing Bing Xue Za Zhi. 2020; 41:145-51.

https://doi.org/10.3760/cma.j.issn.02546450.2020.02.003 PMID:32064853

32. Grasselli G, Zangrillo A, Zanella A, Antonelli M, Cabrini L, Castelli A, Cereda D, Coluccello A, Foti G, Fumagalli R, lotti G, Latronico N, Lorini L, et al, and COVID-19 Lombardy ICU Network. Baseline characteristics and outcomes of 1591 patients infected with SARS-CoV-2 admitted to ICUs of the Lombardy region, Italy. JAMA. 2020; 323:1574-81.

https://doi.org/10.1001/jama.2020.5394

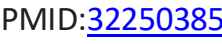

33. Gudbjartsson DF, Helgason A, Jonsson $H$, Magnusson OT, Melsted P, Norddahl GL, Saemundsdottir J, Sigurdsson A, Sulem P, Agustsdottir AB, Eiriksdottir B, Fridriksdottir R, Gardarsdottir EE, et al. Spread of SARSCoV-2 in the Icelandic population. N Engl J Med. 2020; 382:2302-15.

https://doi.org/10.1056/NEJMoa2006100

PMID:32289214

34. Cao Y, Li L, Feng Z, Wan S, Huang P, Sun X, Wen F, Huang $X$, Ning G, Wang W. Comparative genetic analysis of the novel coronavirus (2019-nCoV/SARSCoV-2) receptor ACE2 in different populations. Cell Discov. 2020; 6:11.

https://doi.org/10.1038/s41421-020-0147-1

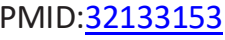


35. Walter LA, McGregor AJ. Sex- and gender-specific observations and implications for COVID-19. West J Emerg Med. 2020; 21:507-09.

https://doi.org/10.5811/westjem.2020.4.47536 PMID:32302282

36. Reardon S. Infections reveal inequality between the sexes. Nature. 2016; 534:447. https://doi.org/10.1038/534447a PMID:27337319

37. Jaillon S, Berthenet K, Garlanda C. Sexual dimorphism in innate immunity. Clin Rev Allergy Immunol. 2019; 56:308-21.

https://doi.org/10.1007/s12016-017-8648-x PMID:28963611

38. The Lancet. The gendered dimensions of COVID-19. Lancet. 2020; 395:1168. https://doi.org/10.1016/S0140-6736(20)30823-0 PMID:32278370

39. Wang B, Li R, Lu Z, Huang Y. Does comorbidity increase the risk of patients with COVID-19: evidence from meta-analysis. Aging (Albany NY). 2020; 12:6049-57. https://doi.org/10.18632/aging.103000 PMID:32267833

40. Chen R, Liang W, Jiang $M$, Guan W, Zhan C, Wang $T$, Tang C, Sang L, Liu J, Ni Z, Hu Y, Liu L, Shan H, et al, and Medical Treatment Expert Group for COVID-19. Risk factors of fatal outcome in hospitalized subjects with coronavirus disease 2019 from a nationwide analysis in China. Chest. 2020; 158:97-105.

https://doi.org/10.1016/j.chest.2020.04.010

PMID:32304772

41. Fang $X$, Li S, Yu H, Wang P, Zhang Y, Chen Z, Li Y, Cheng L, Li W, Jia H, Ma X. Epidemiological, comorbidity factors with severity and prognosis of COVID-19: a systematic review and meta-analysis. Aging (Albany NY). 2020; 12:12493-503.

https://doi.org/10.18632/aging.103579

PMID:32658868

42. Ji HL, Zhao R, Matalon S, Matthay MA. Elevated plasmin(ogen) as a common risk factor for COVID-19 susceptibility. Physiol Rev. 2020; 100:1065-75. https://doi.org/10.1152/physrev.00013.2020 PMID:32216698

43. Richardson S, Hirsch JS, Narasimhan M, Crawford JM, McGinn T, Davidson KW, Barnaby DP, Becker LB, Chelico JD, Cohen SL, Cookingham J, Coppa K, Diefenbach MA, et al, and the Northwell COVID-19 Research Consortium. Presenting characteristics, comorbidities, and outcomes among 5700 patients hospitalized with COVID-19 in the New York City area. JAMA. 2020; 323:2052-59.

https://doi.org/10.1001/jama.2020.6775

PMID:32320003
44. Aggarwal G, Lippi G, Michael Henry B. Cerebrovascular disease is associated with an increased disease severity in patients with Coronavirus Disease 2019 (COVID-19): A pooled analysis of published literature. Int J Stroke. 2020; 15:385-89.

https://doi.org/10.1177/1747493020921664

PMID:32310015

45. Zhao Q, Meng $M$, Kumar $R$, Wu $Y$, Huang J, Lian $N$, Deng $Y$, Lin $S$. The impact of COPD and smoking history on the severity of COVID-19: a systemic review and meta-analysis. J Med Virol. 2020; 92:1915-21. https://doi.org/10.1002/imv.25889 PMID:32293753

46. Mao L, Jin $H$, Wang $M, H u Y$, Chen $S$, He $Q$, Chang J, Hong C, Zhou Y, Wang D, Miao X, Li Y, Hu B. Neurologic manifestations of hospitalized patients with coronavirus disease 2019 in Wuhan, China. JAMA Neurol. 2020; 77:683-90.

https://doi.org/10.1001/jamaneurol.2020.1127 PMID: $\underline{32275288}$

47. Bornstein SR, Rubino F, Khunti K, Mingrone G, Hopkins D, Birkenfeld AL, Boehm B, Amiel S, Holt RI, Skyler JS, DeVries JH, Renard E, Eckel RH, et al. Practical recommendations for the management of diabetes in patients with COVID-19. Lancet Diabetes Endocrinol. 2020; 8:546-50.

https://doi.org/10.1016/S2213-8587(20)30152-2 PMID:32334646

48. Zhu L, She ZG, Cheng X, Qin JJ, Zhang XJ, Cai J, Lei F, Wang $H$, Xie J, Wang $W$, Li $H$, Zhang $P$, Song $X$, et al. Association of blood glucose control and outcomes in patients with COVID-19 and pre-existing type 2 diabetes. Cell Metab. 2020; 31:1068-77.e3.

https://doi.org/10.1016/j.cmet.2020.04.021 PMID: $\underline{32369736}$

49. Clerkin KJ, Fried JA, Raikhelkar J, Sayer G, Griffin JM, Masoumi A, Jain SS, Burkhoff D, Kumaraiah D, Rabbani L, Schwartz A, Uriel N. COVID-19 and cardiovascular disease. Circulation. 2020; 141:1648-55. https://doi.org/10.1161/CIRCULATIONAHA.120.04694 1 PMID: $\underline{32200663}$

50. Madjid M, Safavi-Naeini P, Solomon SD, Vardeny O. Potential effects of coronaviruses on the cardiovascular system: a review. JAMA Cardiol. 2020; 5:831-40.

https://doi.org/10.1001/jamacardio.2020.1286 PMID:32219363

51. Dai M, Liu D, Liu M, Zhou F, Li G, Chen Z, Zhang Z, You $\mathrm{H}$, Wu $\mathrm{M}$, Zheng $\mathrm{Q}$, Xiong $\mathrm{Y}$, Xiong $\mathrm{H}$, Wang $\mathrm{C}$, et al. Patients with cancer appear more vulnerable to SARSCoV-2: a multicenter study during the COVID-19 outbreak. Cancer Discov. 2020; 10:783-91. https://doi.org/10.1158/2159-8290.CD-20-0422 PMID:32345594 
52. Ruscio J. A probability-based measure of effect size: robustness to base rates and other factors. Psychol Methods. 2008; 13:19-30.

https://doi.org/10.1037/1082-989X.13.1.19

PMID:18331151 


\section{SUPPLEMENTARY MATERIALS}

\section{Supplementary Figures}

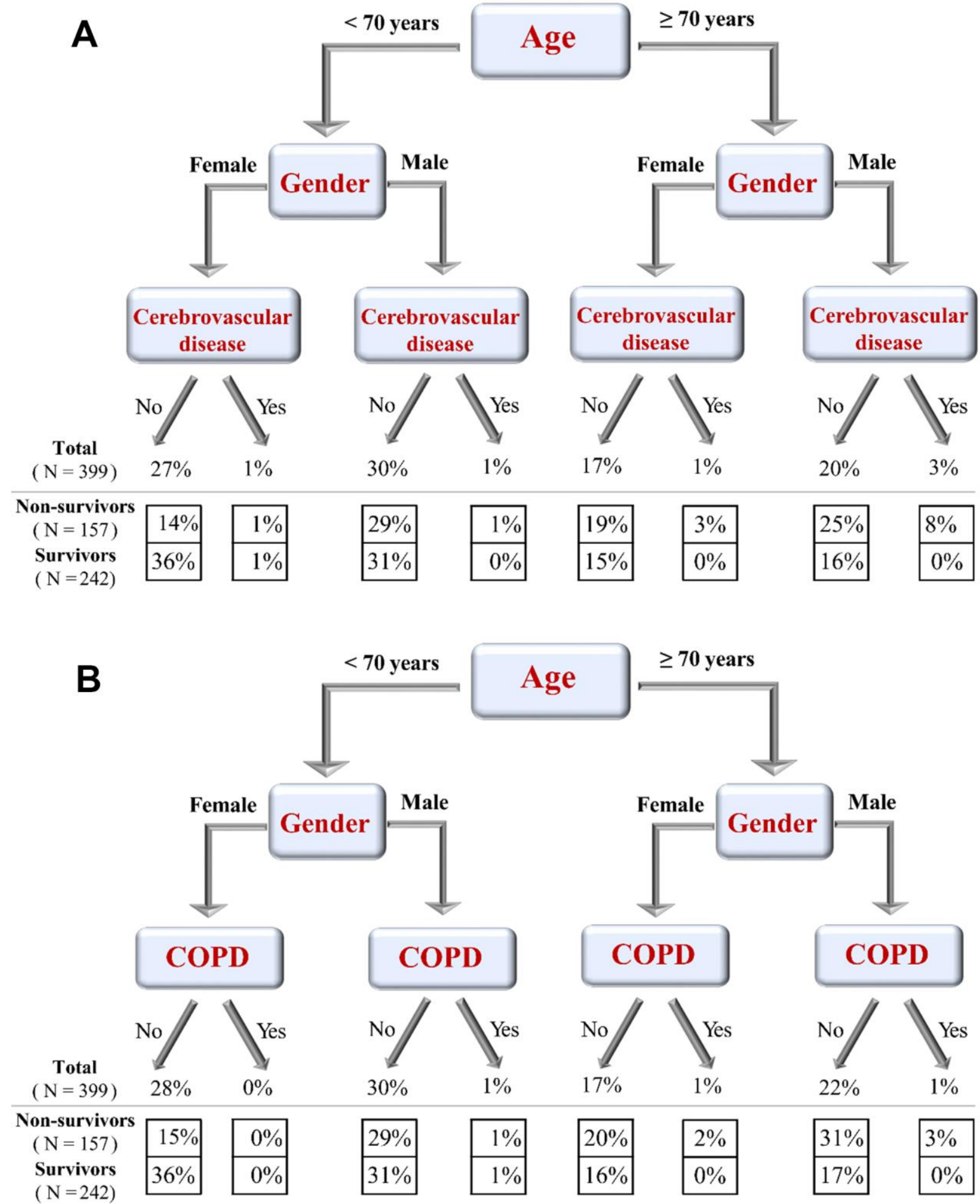

Supplementary Figure 1. A tree model shows proportions of COVID-19 survivors and non-survivors based on patient age and gender plus either cerebrovascular disease (A) or COPD (B). 


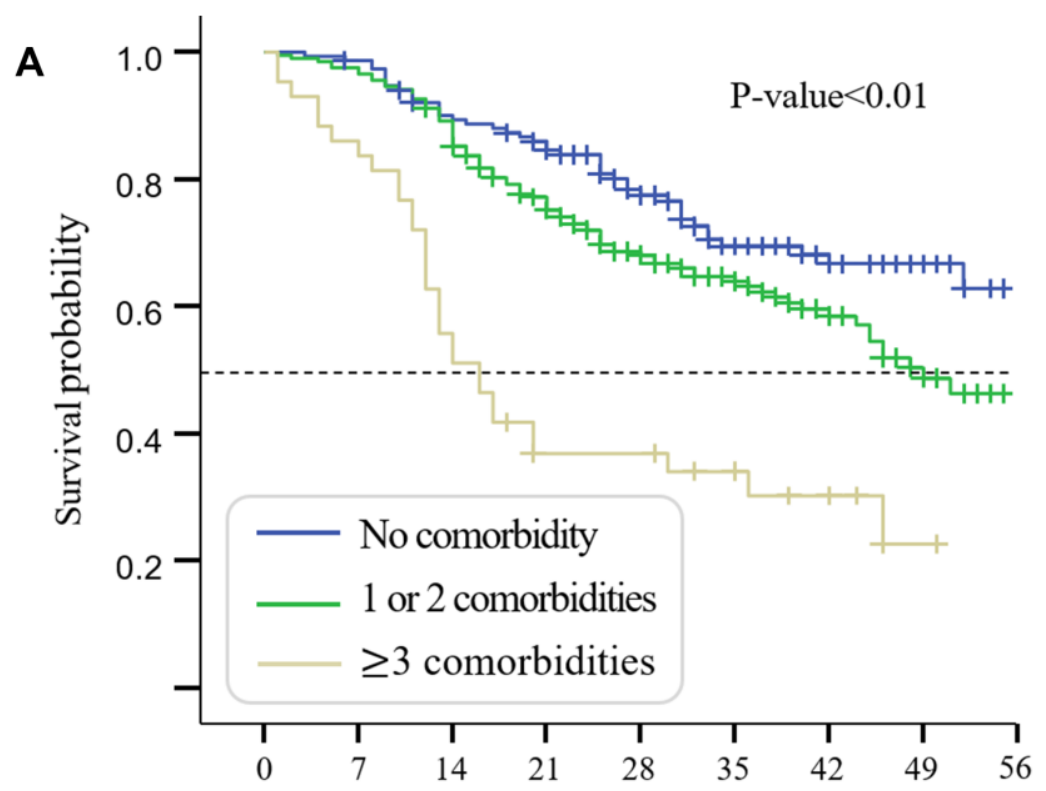

Days from symptom onset to clinical outcome

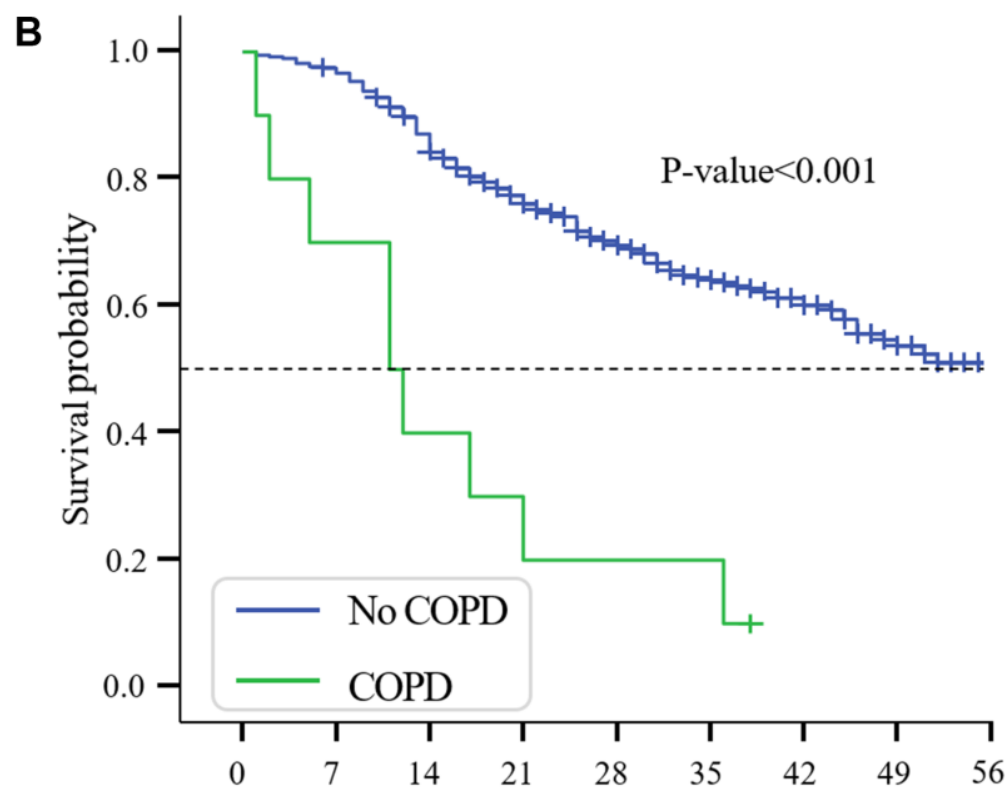

Days from symptom onset to clinical outcome

Supplementary Figure 2. Kaplan-Meier curves of COVID-19 patients. (A) Kaplan-Meier curves of COVID-19 patients with $\geq 3$ comorbidities (brown), 1 or 2 comorbidities (green), or without any comorbidity (blue). (B) Kaplan-Meier curves of COVID-19 patients with or without COPD. Survival probabilities of patients with COPD (green) and without COPD (blue) are shown with the significant difference ( $p$ value $<0.001$ ). 
Females
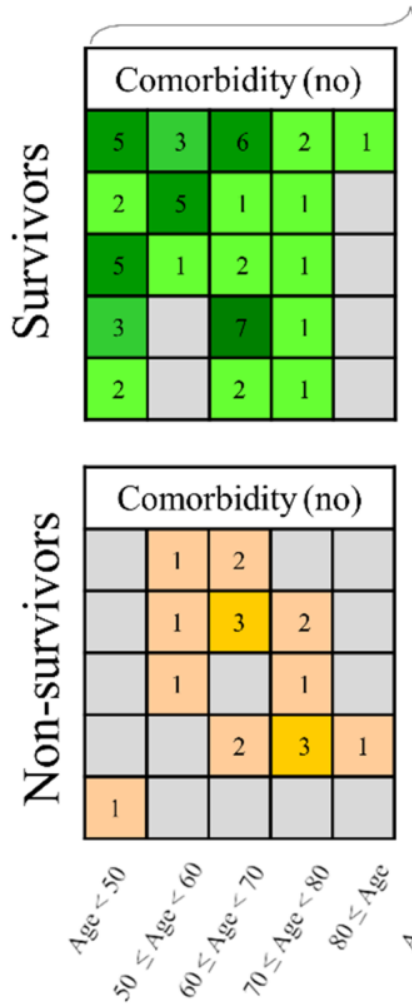

Males

Symptom onset to outcome
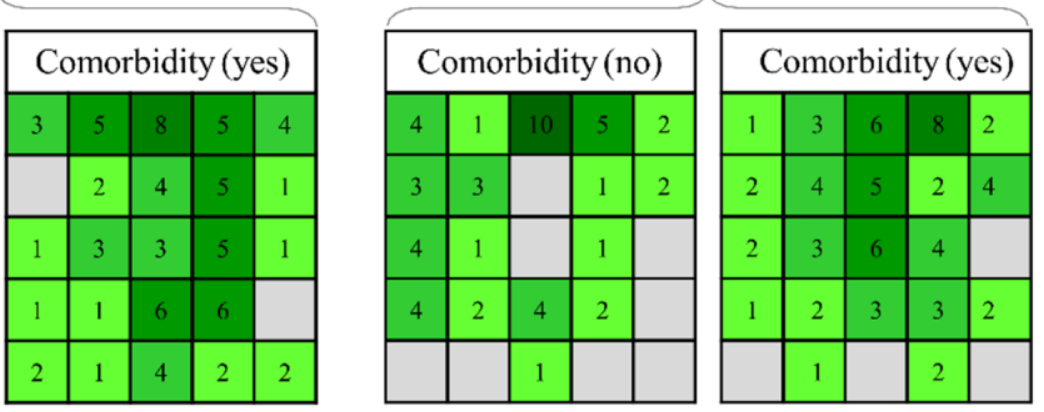

$\geq 43$ days

36 to 42 days

29 to 35 days

22 to 28 days

$\leq 21$ days
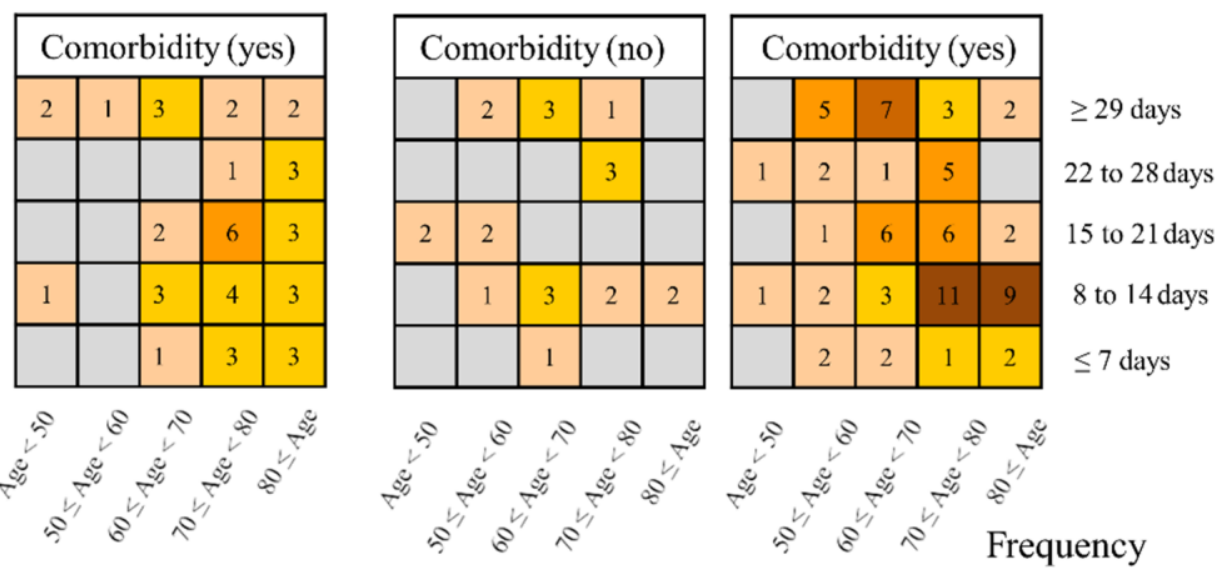

Patient ages

Supplementary Figure 3. Days from symptom onset to clinical outcomes under the conditions of patient age, gender, and comorbidities. 


\section{Supplementary Tables}

Supplementary Table 1. Proportions of comorbidities in females/males and survivors/non-survivors.

\begin{tabular}{lccccccc}
\hline & $\begin{array}{c}\text { Total } \\
(\mathbf{N = 5 9 8})\end{array}$ & $\begin{array}{c}\text { Survivors } \\
(\mathbf{N = 3 5 9 )}\end{array}$ & $\begin{array}{c}\text { Non-survivors } \\
(\mathbf{N = 2 3 9 )}\end{array}$ & P-value & $\begin{array}{c}\text { Females } \\
(\mathbf{N = 3 3 8})\end{array}$ & $\begin{array}{c}\text { Males } \\
(\mathbf{N = 2 6 0})\end{array}$ & P-value \\
\hline Any comorbidity & $412(69 \%)$ & $218(61 \%)$ & $194(81 \%)$ & $<\mathbf{0 . 0 1}$ & $173(67 \%)$ & $239(71 \%)$ & 0.27 \\
1 comorbidity & $209(35 \%)$ & $122(34 \%)$ & $87(36 \%)$ & & $95(37 \%)$ & $114(34 \%)$ & \\
2 comorbidities & $142(24 \%)$ & $73(20 \%)$ & $69(29 \%)$ & $\mathbf{0 . 0 1 6}$ & $58(22 \%)$ & $84(25 \%)$ & 0.20 \\
$\geq 3$ comorbidities & $61(10 \%)$ & $23(6 \%)$ & $38(16 \%)$ & & $20(8 \%)$ & $41(12 \%)$ & \\
Hypertension & $198(33 \%)$ & $109(30 \%)$ & $89(37 \%)$ & 0.08 & $85(33 \%)$ & $113(33 \%)$ & 0.85 \\
Diabetes mellitus & $161(27 \%)$ & $87(24 \%)$ & $74(31 \%)$ & 0.07 & $68(26 \%)$ & $93(28 \%)$ & 0.71 \\
Cardiovascular disease & $178(30 \%)$ & $85(24 \%)$ & $93(39 \%)$ & $<\mathbf{0 . 0 1}$ & $72(28 \%)$ & $106(31 \%)$ & 0.33 \\
Cancers & $47(8 \%)$ & $22(6 \%)$ & $25(11 \%)$ & 0.05 & $15(6 \%)$ & $32(10 \%)$ & 0.10 \\
Cerebrovascular disease & $28(5 \%)$ & $8(2 \%)$ & $20(8 \%)$ & $<\mathbf{0 . 0 1}$ & $9(3 \%)$ & $19(6 \%)$ & 0.22 \\
COPD & $26(4 \%)$ & $4(1 \%)$ & $22(9 \%)$ & $<\mathbf{0 . 0 1}$ & $9(3 \%)$ & $17(5 \%)$ & 0.35 \\
Chronic bronchitis & $16(3 \%)$ & $7(2 \%)$ & $9(4 \%)$ & 0.18 & $4(2 \%)$ & $12(4 \%)$ & 0.13 \\
Chronic liver disease & $11(2 \%)$ & $4(1 \%)$ & $7(3 \%)$ & 0.11 & $4(2 \%)$ & $7(2 \%)$ & 0.62 \\
Digestive disease & $8(1 \%)$ & $3(1 \%)$ & $5(2 \%)$ & 0.19 & $4(2 \%)$ & $4(1 \%)$ & 0.71 \\
Tuberculosis & $6(1 \%)$ & $3(1 \%)$ & $3(1 \%)$ & 0.61 & $1(0.4 \%)$ & $5(1 \%)$ & 0.18 \\
\hline
\end{tabular}

Supplementary Table 2. Mortality-related complications in non-survivors before their death.

\begin{tabular}{lcccc}
\hline & Total $(\mathbf{N}=\mathbf{1 0 2})$ & Female $(\mathbf{N}=\mathbf{3 7})$ & Male (N=65) & P-value \\
\hline Any complication & $102(100 \%)$ & $37(100 \%)$ & $65(100 \%)$ & 1.0 \\
Respiratory failure & $52(51.0 \%)$ & $18(48.6 \%)$ & $34(52.3 \%)$ & 0.72 \\
Acute respiratory distress syndrome & $29(28.4 \%)$ & $9(24.3 \%)$ & $20(30.8 \%)$ & 0.49 \\
Multiple organ failure & $28(27.5 \%)$ & $11(29.7 \%)$ & $17(26.2 \%)$ & 0.70 \\
Shock & $23(22.5 \%)$ & $9(24.3 \%)$ & $14(21.5 \%)$ & 0.75 \\
Hypoxia & $14(13.7 \%)$ & $6(16.2 \%)$ & $8(12.3 \%)$ & 0.58 \\
Coma & $9(8.8 \%)$ & $2(5.4 \%)$ & $7(10.8 \%)$ & 0.36 \\
Hepatic insufficiency & $9(8.8 \%)$ & $3(8.1 \%)$ & $6(9.2 \%)$ & 0.85 \\
Fluid and electrolyte balance & $9(8.8 \%)$ & $4(10.8 \%)$ & $5(7.7 \%)$ & 0.59 \\
Renal insufficiency & $8(7.8 \%)$ & $4(10.8 \%)$ & $4(6.2 \%)$ & 0.40 \\
Heart failure & $7(6.9 \%)$ & $4(10.8 \%)$ & $3(4.6 \%)$ & 0.23 \\
Acute myocardial injury & $5(4.9 \%)$ & $0(0.0 \%)$ & $5(7.7 \%)$ & 0.08 \\
Acidosis & $4(3.9 \%)$ & $2(5.4 \%)$ & $2(3.1 \%)$ & 0.56 \\
Sepsis & $3(2.9 \%)$ & $0(0.0 \%)$ & $3(4.6 \%)$ & 0.18 \\
Disseminated intravascular coagulation & $3(2.9 \%)$ & $0(0.0 \%)$ & $3(4.6 \%)$ & 0.18 \\
\hline
\end{tabular}


Supplementary Table 3.1. Comparisons of baseline characteristics in the original sample and the propensity scorematched sample by gender.

\begin{tabular}{|c|c|c|c|c|c|c|}
\hline & \multicolumn{3}{|c|}{ Original sample } & \multicolumn{3}{|c|}{ Matched sample } \\
\hline & Female(n=184) & Male(n=215) & P-value & Female(n=157) & Male(n=157) & P-value \\
\hline Age, median (IQR) & $66(56.3$ to 73$)$ & 67 (58 to 74$)$ & 0.37 & 65 (55.5 to 73$)$ & 67 (57 to 74$)$ & 0.29 \\
\hline \multicolumn{7}{|l|}{ Region } \\
\hline China & $170(92.4 \%)$ & $196(91.2 \%)$ & 0.66 & $149(94.9 \%)$ & $145(92.4 \%)$ & 0.36 \\
\hline Europe/North America & $14(7.6 \%)$ & $19(8.8 \%)$ & & $8(5.1 \%)$ & $12(7.6 \%)$ & \\
\hline \multicolumn{7}{|l|}{ Signs or symptoms } \\
\hline Fever & $152(82.6 \%)$ & $174(80.9 \%)$ & 0.67 & $130(82.8 \%)$ & $129(82.2 \%)$ & 0.88 \\
\hline Cough & $117(63.6 \%)$ & $139(64.7 \%)$ & 0.83 & $97(61.8 \%)$ & $100(63.7 \%)$ & 0.73 \\
\hline Shortness of breath & $57(31.0 \%)$ & $92(42.8 \%)$ & 0.02 & $54(34.4 \%)$ & $56(35.7 \%)$ & 0.81 \\
\hline Fatigue & $46(25.0 \%)$ & $61(28.4 \%)$ & 0.45 & $44(28.0 \%)$ & $43(27.4 \%)$ & 0.90 \\
\hline Myalgia & $29(15.8 \%)$ & $29(13.5 \%)$ & 0.52 & $21(13.4 \%)$ & $23(14.6 \%)$ & 0.75 \\
\hline Chills & $24(13.0 \%)$ & $39(18.1 \%)$ & 0.16 & $23(14.6 \%)$ & $27(17.2 \%)$ & 0.54 \\
\hline Diarrhea & $28(15.2 \%)$ & $31(14.4 \%)$ & 0.82 & $22(14.0 \%)$ & $23(14.6 \%)$ & 0.87 \\
\hline Headache & $16(8.7 \%)$ & $15(7.0 \%)$ & 0.52 & $12(7.6 \%)$ & $13(8.3 \%)$ & 0.84 \\
\hline Nausea & $11(6.0 \%)$ & $18(8.4 \%)$ & 0.36 & $10(6.4 \%)$ & $11(7.0 \%)$ & 0.82 \\
\hline Appetite loss & $25(13.6 \%)$ & $32(14.9 \%)$ & 0.71 & $22(14.0 \%)$ & $24(15.3 \%)$ & 0.75 \\
\hline \multicolumn{7}{|l|}{ Comorbidity } \\
\hline Any comorbidity & $114(62.0 \%)$ & $141(65.6 \%)$ & 0.45 & $93(59.2 \%)$ & $91(58.0 \%)$ & 0.82 \\
\hline Hypertension & $75(40.8 \%)$ & $88(40.9 \%)$ & 0.97 & $62(39.5 \%)$ & $62(39.5 \%)$ & 1.00 \\
\hline Diabetes mellitus & $50(27.2 \%)$ & $53(24.7 \%)$ & 0.57 & $41(26.1 \%)$ & $35(22.3 \%)$ & 0.43 \\
\hline Cardiovascular disease & $30(16.3 \%)$ & $38(17.7 \%)$ & 0.72 & $20(12.7 \%)$ & $25(15.9 \%)$ & 0.42 \\
\hline Cerebrovascular disease & $9(4.9 \%)$ & $16(7.4 \%)$ & 0.30 & $7(4.5 \%)$ & $10(6.4 \%)$ & 0.45 \\
\hline Chronic liver disease & $3(1.6 \%)$ & $6(2.8 \%)$ & 0.52 & $3(1.9 \%)$ & $1(0.6 \%)$ & 0.63 \\
\hline Digestive disease & $4(2.2 \%)$ & $4(1.9 \%)$ & 1.00 & $3(1.9 \%)$ & $1(0.6 \%)$ & 0.63 \\
\hline Cancer & $4(2.2 \%)$ & $16(7.4 \%)$ & 0.02 & $4(2.5 \%)$ & $2(1.3 \%)$ & 0.68 \\
\hline Chronic bronchitis & $4(2.2 \%)$ & $12(5.6 \%)$ & 0.08 & $4(2.5 \%)$ & $4(2.5 \%)$ & 1.00 \\
\hline COPD & $3(1.6 \%)$ & $8(3.7 \%)$ & 0.20 & $3(1.9 \%)$ & $2(1.3 \%)$ & 1.00 \\
\hline Tuberculosis & $1(0.5 \%)$ & $5(2.3 \%)$ & 0.22 & $1(0.6 \%)$ & $1(0.6 \%)$ & 1.00 \\
\hline
\end{tabular}

IQR: Interquartile range. 
Supplementary Table 3.2. Comparisons of baseline characteristics in the original sample and the propensity scorematched sample by age.

\begin{tabular}{|c|c|c|c|c|c|c|}
\hline & \multicolumn{3}{|c|}{ Original sample } & \multicolumn{3}{|c|}{ Matched sample } \\
\hline & $\begin{array}{l}<70 \text { year } \\
(\mathrm{n}=235)\end{array}$ & $\begin{array}{c}\geq 70 \text { year } \\
(n=164)\end{array}$ & P-value & $\begin{array}{l}<70 \text { year } \\
(n=129)\end{array}$ & $\begin{array}{c}\geq 70 \text { year } \\
(n=129)\end{array}$ & P-value \\
\hline Male & $123(52.3 \%)$ & $92(56.1 \%)$ & 0.46 & $56(43.4 \%)$ & $69(53.5 \%)$ & 0.11 \\
\hline \multicolumn{7}{|l|}{ Region } \\
\hline China & $221(94.0 \%)$ & $145(88.4 \%)$ & & $126(97.6 \%)$ & $119(92.2 \%)$ & \\
\hline European region & $9(3.9 \%)$ & $11(6.7 \%)$ & 0.12 & $1(0.8 \%)$ & $8(6.2 \%)$ & 0.059 \\
\hline North America & $5(2.1 \%)$ & $8(4.9 \%)$ & & $2(1.6 \%)$ & $2(1.6 \%)$ & \\
\hline \multicolumn{7}{|l|}{ Signs or symptoms } \\
\hline Fever & $194(82.6 \%)$ & $132(80.5 \%)$ & 0.60 & $105(81.4 \%)$ & $109(84.5 \%)$ & 0.51 \\
\hline Cough & $159(67.7 \%)$ & $97(59.1 \%)$ & 0.08 & $80(62.0 \%)$ & $80(62.0 \%)$ & 1.00 \\
\hline Shortness of breath & $87(37.0 \%)$ & $62(37.8 \%)$ & 0.87 & $41(31.8 \%)$ & $45(34.9 \%)$ & 0.60 \\
\hline Fatigue & $62(26.4 \%)$ & $45(27.4 \%)$ & 0.82 & $30(23.3 \%)$ & $38(29.5 \%)$ & 0.26 \\
\hline Myalgia & $37(15.7 \%)$ & $21(12.8 \%)$ & 0.41 & $19(14.7 \%)$ & $20(15.5 \%)$ & 0.86 \\
\hline Chills & $40(17.0 \%)$ & $23(14.0 \%)$ & 0.42 & $15(11.6 \%)$ & $19(14.7 \%)$ & 0.46 \\
\hline Diarrhea & $36(15.3 \%)$ & $23(14.0 \%)$ & 0.72 & $24(18.6 \%)$ & $21(16.3 \%)$ & 0.62 \\
\hline Headache & $20(8.5 \%)$ & $11(6.7 \%)$ & 0.51 & $11(8.5 \%)$ & $10(7.8 \%)$ & 0.82 \\
\hline Nausea & $19(8.1 \%)$ & $10(6.1 \%)$ & 0.45 & $8(6.2 \%)$ & $8(6.2 \%)$ & 1.00 \\
\hline Appetite loss & $28(11.9 \%)$ & $29(17.7 \%)$ & 0.11 & $14(10.9 \%)$ & $26(20.2 \%)$ & 0.06 \\
\hline \multicolumn{7}{|l|}{ Comorbidity } \\
\hline Any comorbidity & $127(54.0 \%)$ & $128(78.0 \%)$ & $9.0 \times 10^{-7}$ & $89(69.0 \%)$ & $93(72.1 \%)$ & 0.59 \\
\hline Hypertension & $70(29.8 \%)$ & $93(56.7 \%)$ & $7.4 \times 10^{-8}$ & $60(46.5 \%)$ & $61(47.3 \%)$ & 0.90 \\
\hline Diabetes mellitus & $49(20.9 \%)$ & $54(32,9 \%)$ & 0.007 & $42(32.6 \%)$ & $42(32.6 \%)$ & 1.00 \\
\hline Cardiovascular disease & $23(9.8 \%)$ & $45(27.4 \%)$ & $4.0 \times 10^{-6}$ & $18(14.0 \%)$ & $18(14.0 \%)$ & 1.00 \\
\hline Cerebrovascular disease & $7(3.0 \%)$ & $18(11.0 \%)$ & 0.001 & $5(3.9 \%)$ & $4(3.1 \%)$ & 1.00 \\
\hline Chronic liver disease & $7(3.0 \%)$ & $2(1.2 \%)$ & 0.32 & $3(2.3 \%)$ & $1(0.8 \%)$ & 0.62 \\
\hline Digestive disease & $1(0.4 \%)$ & $7(4.3 \%)$ & 0.01 & $1(0.8 \%)$ & $1(0.8 \%)$ & 1.00 \\
\hline Cancer & $8(3.4 \%)$ & $12(7.3 \%)$ & 0.08 & $3(2.3 \%)$ & $9(7.0 \%)$ & 0.08 \\
\hline Chronic bronchitis & $6(2.6 \%)$ & $10(6.1 \%)$ & 0.08 & $2(1.6 \%)$ & $8(6.2 \%)$ & 0.05 \\
\hline COPD & $4(1.7 \%)$ & $7(4.3 \%)$ & 0.13 & $3(2.3 \%)$ & $3(2.3 \%)$ & 1.00 \\
\hline Tuberculosis & $5(2.1 \%)$ & $1(0.6 \%)$ & 0.41 & $4(3.1 \%)$ & $0(0.0 \%)$ & 0.12 \\
\hline
\end{tabular}


Supplementary Table 3.3. Comparisons of baseline characteristics in the original sample and the propensity scorematched sample by shortness of breath.

\begin{tabular}{|c|c|c|c|c|c|c|}
\hline & \multicolumn{3}{|c|}{ Original sample } & \multicolumn{3}{|c|}{ Matched sample } \\
\hline & $\begin{array}{c}\text { Shortness of } \\
\text { breath }(n=149)\end{array}$ & $\begin{array}{c}\text { Non-Shortness } \\
\text { of breath } \\
(\mathbf{n}=\mathbf{2 5 0})\end{array}$ & P-value & $\begin{array}{c}\text { Shortness of } \\
\text { breath } \\
(\mathbf{n}=133)\end{array}$ & $\begin{array}{c}\text { Non-Shortness } \\
\text { of breath } \\
(\mathbf{n}=133)\end{array}$ & P-value \\
\hline Male & $92(61.7 \%)$ & $123(49.2 \%)$ & 0.02 & $81(60.9 \%)$ & $78(58.6 \%)$ & 0.71 \\
\hline Age, median (IQR) & 67 (58 to 73.5$)$ & 66 (56 to 74$)$ & 0.29 & 66 (58 to 73$)$ & $64(55$ to 73$)$ & 0.12 \\
\hline \multicolumn{7}{|l|}{ Region } \\
\hline China & $129(86.6 \%)$ & $237(94.8 \%)$ & 0.004 & $123(92.5 \%)$ & $120(90.2 \%)$ & 0.51 \\
\hline Europe/North America & $20(13.4 \%)$ & $13(5.2 \%)$ & & $10(7.5 \%)$ & $13(9.8 \%)$ & \\
\hline \multicolumn{7}{|l|}{ Signs or symptoms } \\
\hline Fever & $120(80.5 \%)$ & $206(82.4 \%)$ & 0.64 & $110(82.7 \%)$ & $109(82.0 \%)$ & 0.87 \\
\hline Cough & $100(67.1 \%)$ & $156(62.4 \%)$ & 0.34 & $92(69.2 \%)$ & $81(60.9 \%)$ & 0.16 \\
\hline Fatigue & $36(24.2 \%)$ & $71(28.4 \%)$ & 0.36 & $34(25.6 \%)$ & $37(27.8 \%)$ & 0.68 \\
\hline Myalgia & $27(18.1 \%)$ & $31(12.4 \%)$ & 0.12 & $26(19.5 \%)$ & $24(18.0 \%)$ & 0.75 \\
\hline Chills & $31(20.8 \%)$ & $32(12.8 \%)$ & 0.03 & $26(19.5 \%)$ & $25(18.8 \%)$ & 0.88 \\
\hline Diarrhea & $24(16.1 \%)$ & $35(14.0 \%)$ & 0.57 & $21(15.8 \%)$ & $17(12.8 \%)$ & 0.48 \\
\hline Headache & $12(8.1 \%)$ & $19(7.6 \%)$ & 0.87 & $10(7.5 \%)$ & $10(7.5 \%)$ & 1.00 \\
\hline Nausea & $11(7.4 \%)$ & $18(7.2 \%)$ & 0.95 & $10(7.5 \%)$ & $8(6.0 \%)$ & 0.63 \\
\hline Appetite loss & $19(12.8 \%)$ & $38(15.2 \%)$ & 0.50 & $18(13.5 \%)$ & $17(12.8 \%)$ & 0.86 \\
\hline \multicolumn{7}{|l|}{ Comorbidity } \\
\hline Any comorbidity & $100(67.1 \%)$ & $155(62.0 \%)$ & 0.30 & $84(63.2 \%)$ & $83(62.4 \%)$ & 0.90 \\
\hline Hypertension & $59(39.6 \%)$ & $104(41.6 \%)$ & 0.69 & $50(37.6 \%)$ & $51(38.3 \%)$ & 0.90 \\
\hline Diabetes mellitus & $42(28.2 \%)$ & $61(24.4 \%)$ & 0.40 & $37(27.8 \%)$ & $33(24.8 \%)$ & 0.58 \\
\hline Cardiovascular disease & $35(23.5 \%)$ & $33(13.2 \%)$ & 0.008 & $23(17.3 \%)$ & $18(13.5 \%)$ & 0.40 \\
\hline Cerebrovascular disease & $12(8.1 \%)$ & $13(5.2 \%)$ & 0.26 & $9(6.8 \%)$ & $3(2.3 \%)$ & 0.08 \\
\hline Chronic liver disease & $2(1.3 \%)$ & $7(2.8 \%)$ & 0.49 & $2(1.5 \%)$ & $2(1.5 \%)$ & 1.00 \\
\hline Digestive disease & $4(2.7 \%)$ & $4(1.6 \%)$ & 0.48 & $4(3.0 \%)$ & $0(0.0 \%)$ & 0.12 \\
\hline Cancer & $6(4.0 \%)$ & $14(5.6 \%)$ & 0.49 & $6(4.5 \%)$ & $6(4.5 \%)$ & 1.00 \\
\hline Chronic bronchitis & $6(4.0 \%)$ & $10(4.0 \%)$ & 0.99 & $6(4.5 \%)$ & $4(3.0 \%)$ & 0.52 \\
\hline COPD & $9(6.0 \%)$ & $2(0.8 \%)$ & 0.003 & $1(0.8 \%)$ & $2(1.5 \%)$ & 1.00 \\
\hline Tuberculosis & $1(0.7 \%)$ & $5(2.0 \%)$ & 0.42 & $1(0.8 \%)$ & $4(3.0 \%)$ & 0.37 \\
\hline
\end{tabular}

IQR: interquartile range. 
Supplementary Table 3.4. Comparisons of baseline characteristics in the original sample and the propensity scorematched sample by any comorbidity.

\begin{tabular}{|c|c|c|c|c|c|c|}
\hline & \multicolumn{3}{|c|}{ Original sample } & \multicolumn{3}{|c|}{ Matched sample } \\
\hline & $\begin{array}{c}\text { Comorbidity } \\
(\mathbf{n}=255)\end{array}$ & $\begin{array}{c}\begin{array}{c}\text { Non- } \\
\text { comorbidity } \\
(n=144)\end{array} \\
\end{array}$ & P-value & $\begin{array}{c}\text { Comorbidity } \\
(\mathrm{n}=123)\end{array}$ & $\begin{array}{c}\text { Non- } \\
\text { comorbidity } \\
(n=123)\end{array}$ & P-value \\
\hline Male & $141(55.3 \%)$ & $74(51.4 \%)$ & 0.45 & $64(52.0 \%)$ & $63(51.2 \%)$ & 0.90 \\
\hline Age, median (IQR) & 70 (62 to 76$)$ & $62(50$ to 69.8$)$ & $2.5 \times 10^{-10}$ & $64(56$ to 70$)$ & 63 (57 to 70$)$ & 0.92 \\
\hline \multicolumn{7}{|l|}{ Region } \\
\hline China & $223(87.5 \%)$ & $143(99.3 \%)$ & $3.6 \times 10^{-5}$ & $121(98.4 \%)$ & $122(99.2 \%)$ & 1.00 \\
\hline Europe/North America & $32(12.5 \%)$ & $1(0.7 \%)$ & & $2(1.6 \%)$ & $1(0.8 \%)$ & \\
\hline \multicolumn{7}{|l|}{ Signs or symptoms } \\
\hline Fever & $204(80.0 \%)$ & $122(84.7 \%)$ & 0.24 & $104(84.6 \%)$ & $105(85.4 \%)$ & 0.86 \\
\hline Cough & $159(62.4 \%)$ & $97(67.4 \%)$ & 0.32 & $79(64.2 \%)$ & $82(66.7 \%)$ & 0.69 \\
\hline Shortness of breath & $100(39.2 \%)$ & $49(34.0 \%)$ & 0.30 & $44(35.8 \%)$ & $46(37.4 \%)$ & 0.79 \\
\hline Fatigue & $67(26.3 \%)$ & $40(27.8 \%)$ & 0.75 & $35(28.5 \%)$ & $34(27.6 \%)$ & 0.89 \\
\hline Myalgia & $34(13.3 \%)$ & $24(16.7 \%)$ & 0.36 & $19(15.4 \%)$ & $22(17.9 \%)$ & 0.61 \\
\hline Chills & $35(13.7 \%)$ & $28(19.4 \%)$ & 0.13 & $18(14.6 \%)$ & $23(18.7 \%)$ & 0.39 \\
\hline Diarrhea & $38(14.9 \%)$ & $21(14.6 \%)$ & 0.93 & $20(16.3 \%)$ & $19(15.4 \%)$ & 0.86 \\
\hline Headache & $18(7.1 \%)$ & $13(9.0 \%)$ & 0.48 & $11(8.9 \%)$ & $9(7.3 \%)$ & 0.64 \\
\hline Nausea & $18(7.1 \%)$ & $11(7.6 \%)$ & 0.83 & $12(9.8 \%)$ & $8(6.5 \%)$ & 0.35 \\
\hline Appetite loss & $35(13.7 \%)$ & $22(15.3 \%)$ & 0.67 & $19(15.4 \%)$ & $18(14.6 \%)$ & 0.86 \\
\hline
\end{tabular}

IQR: interquartile range. 
Supplementary Table 3.5. Comparisons of baseline characteristics in the original sample and the propensity scorematched sample by cardiovascular disease.

\begin{tabular}{|c|c|c|c|c|c|c|}
\hline & \multicolumn{3}{|c|}{ Original sample } & \multicolumn{3}{|c|}{ Matched sample } \\
\hline & $\begin{array}{c}\text { Cardiovascula } \\
\text { r disease } \\
(n=68)\end{array}$ & $\begin{array}{c}\text { Non- } \\
\text { cardiovascular } \\
\text { disease } \\
(\mathbf{n}=331) \\
\end{array}$ & P-value & $\begin{array}{c}\text { Cardiovascula } \\
\text { r disease } \\
(\mathbf{n}=58)\end{array}$ & $\begin{array}{c}\text { Non- } \\
\text { cardiovascular } \\
\text { disease } \\
(\mathbf{n}=58) \\
\end{array}$ & P-value \\
\hline Male & $38(55.9 \%)$ & $177(53.5 \%)$ & 0.72 & $31(53.4 \%)$ & $34(58.6 \%)$ & 0.58 \\
\hline Age, median (IQR) & 73.5 (67 to 82$)$ & 65 (56 to 72$)$ & $2.1 \times 10^{-10}$ & 73 (66 to 80$)$ & 73 (68 to 81$)$ & 0.66 \\
\hline \multicolumn{7}{|l|}{ Region } \\
\hline China & $55(80.9 \%)$ & $311(94.0 \%)$ & $3.6 \times 10^{-4}$ & $51(87.9 \%)$ & $55(94.8 \%)$ & 0.19 \\
\hline Europe/North America & $13(19.1 \%)$ & $20(6.0 \%)$ & & $7(12.1 \%)$ & $3(5.2 \%)$ & \\
\hline \multicolumn{7}{|l|}{ Signs or symptoms } \\
\hline Fever & $50(73.5 \%)$ & $276(83.4 \%)$ & 0.06 & $45(77.6 \%)$ & $45(77.6 \%)$ & 1.00 \\
\hline Cough & $41(60.3 \%)$ & $215(65.0 \%)$ & 0.47 & $36(62.1 \%)$ & $28(48.3 \%)$ & 0.14 \\
\hline Shortness of breath & $35(51.5 \%)$ & $114(34.4 \%)$ & 0.008 & $25(43.1 \%)$ & $26(44.8 \%)$ & 0.85 \\
\hline Fatigue & $14(20.6 \%)$ & $93(28.1 \%)$ & 0.20 & $13(22.4 \%)$ & $15(25.9 \%)$ & 0.66 \\
\hline Myalgia & $6(8.8 \%)$ & $52(15.7 \%)$ & 0.14 & $6(10.3 \%)$ & $7(12.1 \%)$ & 0.77 \\
\hline Chills & $11(16.2 \%)$ & $52(15.7 \%)$ & 0.92 & $10(17.2 \%)$ & $8(13.8 \%)$ & 0.61 \\
\hline Diarrhea & $9(13.2 \%)$ & $50(15.1 \%)$ & 0.69 & $8(13.8 \%)$ & $8(13.8 \%)$ & 1.00 \\
\hline Headache & $5(7.4 \%)$ & $26(7.9 \%)$ & 0.89 & $5(8.6 \%)$ & $4(6.9 \%)$ & 1.00 \\
\hline Nausea & $3(4.4 \%)$ & $26(7.9 \%)$ & 0.44 & $3(5.2 \%)$ & $3(5.2 \%)$ & 1.00 \\
\hline Appetite loss & $5(7.4 \%)$ & $52(15.7 \%)$ & 0.07 & $5(8.6 \%)$ & $6(10.3 \%)$ & 0.75 \\
\hline \multicolumn{7}{|l|}{ Comorbidity } \\
\hline Any comorbidity & $68(100.0 \%)$ & $187(56.5 \%)$ & $1.0 \times 10^{-11}$ & $58(100.0 \%)$ & $58(100.0 \%)$ & - \\
\hline Hypertension & $43(63.2 \%)$ & $120(36.3 \%)$ & $3.7 \times 10^{-5}$ & $36(62.1 \%)$ & $34(58.6 \%)$ & 0.70 \\
\hline Diabetes mellitus & $24(35.3 \%)$ & $79(23.9 \%)$ & 0.05 & $20(34.5 \%)$ & $27(46.6 \%)$ & 0.19 \\
\hline Cerebrovascular disease & $10(14.7 \%)$ & $15(4.5 \%)$ & 0.004 & $6(10.3 \%)$ & $8(13.8 \%)$ & 0.57 \\
\hline Chronic liver disease & $2(2.9 \%)$ & $7(2.1 \%)$ & 0.65 & $2(3.4 \%)$ & $2(3.4 \%)$ & 1.00 \\
\hline Digestive disease & $3(4.4 \%)$ & $5(1.5 \%)$ & 0.14 & $3(5.2 \%)$ & $3(5.2 \%)$ & 1.00 \\
\hline Cancer & $5(7.4 \%)$ & $15(4.5 \%)$ & 0.36 & $5(8.6 \%)$ & $4(6.9 \%)$ & 1.00 \\
\hline Chronic bronchitis & $5(7.4 \%)$ & $11(3.3 \%)$ & 0.17 & $4(6.9 \%)$ & $4(6.9 \%)$ & 1.00 \\
\hline COPD & $8(11.8 \%)$ & $3(0.9 \%)$ & $5.3 \times 10^{-5}$ & $3(5.2 \%)$ & $2(3.4 \%)$ & 1.00 \\
\hline Tuberculosis & $2(2.9 \%)$ & $4(1.2 \%)$ & 0.27 & $2(3.4 \%)$ & $0(0.0 \%)$ & 0.50 \\
\hline
\end{tabular}

IQR: interquartile range. 
Supplementary Table 3.6. Comparisons of baseline characteristics in the original sample and the propensity score matched sample by cerebrovascular disease.

\begin{tabular}{|c|c|c|c|c|c|c|}
\hline & \multicolumn{3}{|c|}{ Original sample } & \multicolumn{3}{|c|}{ Matched sample } \\
\hline & $\begin{array}{c}\text { Cerebrovascular } \\
\text { disease } \\
(\mathbf{n}=25)\end{array}$ & $\begin{array}{c}\text { Non- } \\
\text { cerebrovascular } \\
\text { disease } \\
(\mathbf{n = 3 7 4})\end{array}$ & P-value & $\begin{array}{c}\text { Cerebrovascular } \\
\text { disease } \\
(\mathbf{n}=25)\end{array}$ & $\begin{array}{c}\text { Non- } \\
\text { cerebrovascular } \\
\text { disease } \\
(\mathbf{n}=\mathbf{2 5})\end{array}$ & P-value \\
\hline Male & $16(64.0 \%)$ & $199(53.2 \%)$ & 0.30 & $16(64.0 \%)$ & $9(36.0 \%)$ & 0.05 \\
\hline Age, median (IQR) & $78(65.5$ to 84$)$ & 66 (57 to 73$)$ & $2.0 \times 10^{-4}$ & $78(65.5$ to 84$)$ & $74(65.5$ to 83$)$ & 0.83 \\
\hline \multicolumn{7}{|l|}{ Region } \\
\hline China & $21(84.0 \%)$ & $345(92.2 \%)$ & 0.14 & $21(84.0 \%)$ & $25(100 \%)$ & 0.11 \\
\hline Europe/North America & $4(16.0 \%)$ & $29(7.8 \%)$ & & $4(16.0 \%)$ & $0(0.0 \%)$ & \\
\hline \multicolumn{7}{|l|}{ Signs or symptoms } \\
\hline Fever & $19(76.0 \%)$ & $307(82.1 \%)$ & 0.43 & $19(76.0 \%)$ & $18(72.0 \%)$ & 0.75 \\
\hline Cough & $13(52.0 \%)$ & $243(65.0 \%)$ & 0.19 & $13(52.0 \%)$ & $13(52.0 \%)$ & 1.00 \\
\hline Shortness of breath & $12(48.0 \%)$ & $137(36.6 \%)$ & 0.26 & $12(48.0 \%)$ & $8(32.0 \%)$ & 0.25 \\
\hline Fatigue & $6(24.0 \%)$ & $101(27.0 \%)$ & 0.74 & $6(24.0 \%)$ & $6(24.0 \%)$ & 1.00 \\
\hline Myalgia & $4(16.0 \%)$ & $54(14.4 \%)$ & 0.77 & $4(16.0 \%)$ & $2(8.0 \%)$ & 0.67 \\
\hline Chills & $4(16.0 \%)$ & $59(15.8 \%)$ & 1.00 & $4(16.0 \%)$ & $0(0.0 \%)$ & 0.11 \\
\hline Diarrhea & $2(8.0 \%)$ & $57(15.2 \%)$ & 0.56 & $2(8.0 \%)$ & $4(16.0 \%)$ & 0.67 \\
\hline Headache & $3(12.0 \%)$ & $28(7.5 \%)$ & 0.43 & $3(12.0 \%)$ & $1(4.0 \%)$ & 0.61 \\
\hline Nausea & $4(16.0 \%)$ & $25(6.7 \%)$ & 0.10 & $4(16.0 \%)$ & $1(4.0 \%)$ & 0.35 \\
\hline Appetite loss & $3(12.0 \%)$ & $54(14.4 \%)$ & 1.00 & $3(12.0 \%)$ & $2(8.0 \%)$ & 1.00 \\
\hline \multicolumn{7}{|l|}{ Comorbidity } \\
\hline Any comorbidity & $25(100.0 \%)$ & $230(61.5 \%)$ & $1.0 \times 10^{-4}$ & $25(100.0 \%)$ & $25(100.0 \%)$ & - \\
\hline Hypertension & $18(72.0 \%)$ & $145(38.8 \%)$ & 0.001 & $18(72.0 \%)$ & $20(80.0 \%)$ & 0.51 \\
\hline Diabetes mellitus & $10(40.0 \%)$ & $93(24.9 \%)$ & 0.09 & $10(40.0 \%)$ & $14(56.0 \%)$ & 0.26 \\
\hline Cardiovascular disease & $10(40.0 \%)$ & $58(15.5 \%)$ & 0.004 & $10(40.0 \%)$ & $11(44.0 \%)$ & 0.77 \\
\hline Chronic liver disease & $0(0.0 \%)$ & $9(2.4 \%)$ & 1.00 & $0(0.0 \%)$ & $0(0.0 \%)$ & - \\
\hline Digestive disease & $2(8.0 \%)$ & $6(1.6 \%)$ & 0.08 & $2(8.0 \%)$ & $0(0.0 \%)$ & 0.49 \\
\hline Cancer & $2(8.0 \%)$ & $18(4.8 \%)$ & 0.36 & $2(8.0 \%)$ & $1(4.0 \%)$ & 1.00 \\
\hline Chronic bronchitis & $2(8.0 \%)$ & $14(3.7 \%)$ & 0.27 & $2(8.0 \%)$ & $1(4.0 \%)$ & 1.00 \\
\hline COPD & $1(4.0 \%)$ & $10(2.7 \%)$ & 0.51 & $1(4.0 \%)$ & $0(0.0 \%)$ & 1.00 \\
\hline Tuberculosis & $0(0.0 \%)$ & $6(1.6 \%)$ & 1.00 & $0(0.0 \%)$ & $1(4.0 \%)$ & 1.00 \\
\hline
\end{tabular}

IQR: interquartile range. 
Supplementary Table 3.7. Comparisons of baseline characteristics in the original sample and the propensity score matched sample by COPD.

\begin{tabular}{|c|c|c|c|c|c|c|}
\hline & \multicolumn{3}{|c|}{ Original sample } & \multicolumn{3}{|c|}{ Matched sample } \\
\hline & $\begin{array}{l}\text { COPD } \\
(n=11)\end{array}$ & $\begin{array}{c}\text { Non-COPD } \\
(\mathbf{n}=\mathbf{3 8 8})\end{array}$ & P-value & $\begin{array}{c}\text { COPD } \\
(\mathbf{n}=9)\end{array}$ & $\begin{array}{c}\text { Non-COPD } \\
(\mathbf{n}=9)\end{array}$ & P-value \\
\hline Male & $8(72.7 \%)$ & $207(53.4 \%)$ & 0.20 & $8(88.9 \%)$ & $5(55.6 \%)$ & 0.29 \\
\hline Age, median (IQR) & 78 (66 to 84$)$ & $66(57$ to 73$)$ & 0.01 & 75 (65 to 81$)$ & $72(67$ to 82$)$ & 0.93 \\
\hline \multicolumn{7}{|l|}{ Region } \\
\hline China & $7(63.6 \%)$ & $359(92.5 \%)$ & 0.009 & $7(77.8 \%)$ & $7(77.8 \%)$ & 1.00 \\
\hline Europe/North America & $4(36.4 \%)$ & $29(7.5 \%)$ & & $2(22.2 \%)$ & $2(22.2 \%)$ & \\
\hline \multicolumn{7}{|l|}{ Signs or symptoms } \\
\hline Fever & $6(54.5 \%)$ & $320(82.5 \%)$ & 0.03 & $6(66.7 \%)$ & $6(66.7 \%)$ & 1.00 \\
\hline Cough & $7(63.6 \%)$ & $249(64.2 \%)$ & 1.00 & $6(66.7 \%)$ & $6(66.7 \%)$ & 1.00 \\
\hline Shortness of breath & $9(81.8 \%)$ & $140(36.1 \%)$ & 0.003 & $7(77.8 \%)$ & $6(66.7 \%)$ & 1.00 \\
\hline Fatigue & $2(18.2 \%)$ & $105(27.1 \%)$ & 0.73 & $2(22.2 \%)$ & $3(33.3 \%)$ & 1.00 \\
\hline Myalgia & $1(9.1 \%)$ & $57(14.7 \%)$ & 1.00 & $1(11.1 \%)$ & $1(11.1 \%)$ & 1.00 \\
\hline Chills & $2(18.2 \%)$ & $61(15.7 \%)$ & 0.69 & $2(22.2 \%)$ & $0(0.0 \%)$ & 0.47 \\
\hline Diarrhea & $3(27.3 \%)$ & $56(14.4 \%)$ & 0.21 & $3(33.3 \%)$ & $1(11.1 \%)$ & 0.58 \\
\hline Headache & $2(18.2 \%)$ & $29(7.5 \%)$ & 0.21 & $2(22.2 \%)$ & $1(11.1 \%)$ & 1.00 \\
\hline Nausea & $1(9.1 \%)$ & $28(7.2 \%)$ & 0.57 & $1(11.1 \%)$ & $0(0.0 \%)$ & 1.00 \\
\hline Appetite loss & $1(9.1 \%)$ & $56(14.4 \%)$ & 1.00 & $1(11.1 \%)$ & $1(11.1 \%)$ & 1.00 \\
\hline \multicolumn{7}{|l|}{ Comorbidity } \\
\hline Any comorbidity & $11(100 \%)$ & $244(62.9 \%)$ & 0.009 & $9(100 \%)$ & $8(88.9 \%)$ & 1.00 \\
\hline Hypertension & $6(54.5 \%)$ & $157(40.5 \%)$ & 0.37 & $4(44.4 \%)$ & $6(66.7 \%)$ & 0.64 \\
\hline Diabetes mellitus & $5(45.5 \%)$ & $98(25.3 \%)$ & 0.16 & $4(44.4 \%)$ & $4(44.4 \%)$ & 1.00 \\
\hline Cardiovascular disease & $8(72.7 \%)$ & $60(15.5 \%)$ & $5.3 \times 10^{-5}$ & $6(66.7 \%)$ & $7(77.8 \%)$ & 1.00 \\
\hline Cerebrovascular disease & $1(9.1 \%)$ & $24(6.2 \%)$ & 0.51 & $1(11.1 \%)$ & $2(22.2 \%)$ & 1.00 \\
\hline Chronic liver disease & $0(0.0 \%)$ & $9(2.3 \%)$ & 1.00 & $0(0.0 \%)$ & $0(0.0 \%)$ & - \\
\hline Digestive disease & $0(0.0 \%)$ & $8(2.1 \%)$ & 1.00 & $0(0.0 \%)$ & $0(0.0 \%)$ & - \\
\hline Cancer & $1(9.1 \%)$ & $19(4.9 \%)$ & 0.44 & $1(11.1 \%)$ & $0(0.0 \%)$ & 1.00 \\
\hline Chronic bronchitis & $1(9.1 \%)$ & $15(3.9 \%)$ & 0.37 & $1(11.1 \%)$ & $0(0.0 \%)$ & 1.00 \\
\hline Tuberculosis & $0(0.0 \%)$ & $6(1.5 \%)$ & 1.00 & $0(0.0 \%)$ & $0(0.0 \%)$ & - \\
\hline
\end{tabular}

IQR: interquartile range. 
Supplementary Table 4. Retrieved online records of COVID-19 patients in China, European regions, and North America.

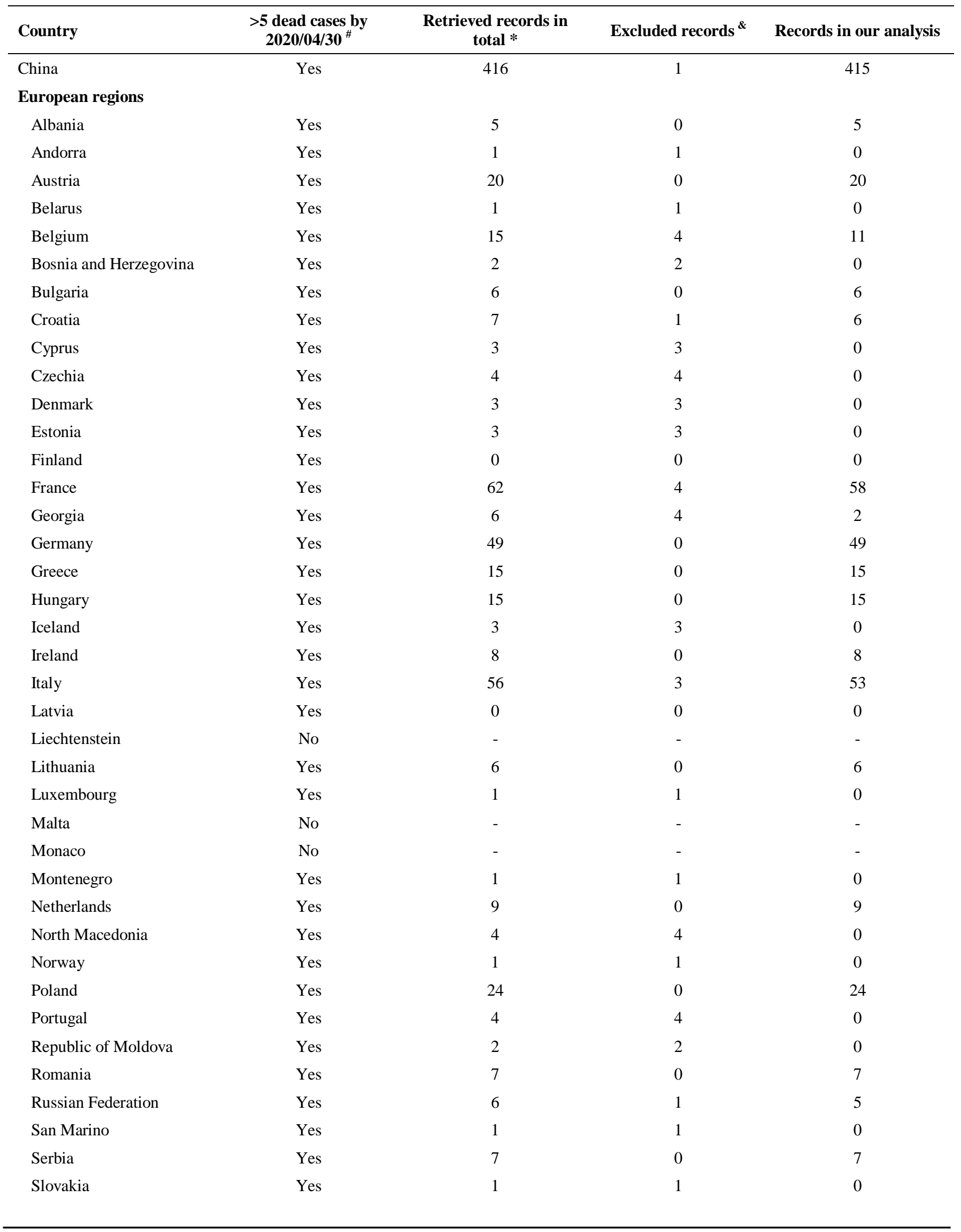




\begin{tabular}{|c|c|c|c|c|}
\hline Slovenia & Yes & 3 & 3 & 0 \\
\hline Spain & Yes & 201 & 76 & 125 \\
\hline Sweden & Yes & 1 & 1 & 0 \\
\hline Switzerland & Yes & 4 & 4 & 0 \\
\hline The United Kingdom & Yes & 35 & 0 & 35 \\
\hline Ukraine & Yes & 2 & 2 & 0 \\
\hline \multicolumn{5}{|l|}{ North America } \\
\hline United States of America & Yes & 191 & 24 & 167 \\
\hline Antigua and Barbuda & No & - & - & 0 \\
\hline Bahamas & Yes & 1 & 1 & 0 \\
\hline Barbados & Yes & 1 & 1 & 0 \\
\hline Belize & No & - & - & 0 \\
\hline Canada & Yes & 5 & 2 & 3 \\
\hline Costa Rica & Yes & 2 & 2 & 0 \\
\hline Cuba & Yes & 6 & 0 & 6 \\
\hline Dominica & No & - & - & 0 \\
\hline Dominican Republic & Yes & 4 & 4 & 0 \\
\hline El Salvador & Yes & 0 & 0 & 0 \\
\hline Grenada & No & - & - & 0 \\
\hline Guatemala & Yes & 1 & 1 & 0 \\
\hline Haiti & Yes & 2 & 2 & 0 \\
\hline Honduras & Yes & 4 & 4 & 0 \\
\hline Jamaica & Yes & 2 & 2 & 0 \\
\hline Mexico & Yes & 18 & 0 & 18 \\
\hline Nicaragua & Yes & 1 & 1 & 0 \\
\hline Panama & Yes & 3 & 3 & 0 \\
\hline Saint Kitts and Nevis & No & - & - & 0 \\
\hline Saint Lucia & No & - & - & 0 \\
\hline $\begin{array}{l}\text { Saint Vincent and the } \\
\text { Grenadines }\end{array}$ & No & - & - & 0 \\
\hline Trinidad and Tobago & Yes & 2 & 2 & 0 \\
\hline Total & & 1267 & 192 & 1075 \\
\hline
\end{tabular}

\#: "Yes" indicates a country with $\geq 5$ dead cases by $2020 / 04 / 30$. The number of dead cases was retrieved based on the situation report of COVID-19 from the WHO (date: April 30, 2020).

$*$ : Total number of retrieved online records from each country.

\&: Records were excluded if they failed to fulfill four selection criteria:

(i) Patients did not receive remdesivir;

(ii) Patients did not receive dexamethasone;

(iii) Patients cases were hospitalized after May 1 and had missing data of therapy;

(iv) Countries with limited number of COVID-19 cases in the dataset $(<5)$. 


\section{Supplementary Method}

\section{Supplementary Method 1: Discharge criteria of COVID-19 patients}

Based on the New Coronavirus Diagnosis and Treatment Guidelines in China, patients were discharged if they fulfilled all three conditions:

(i) At least two consecutive results of undetectable SARS-CoV-2 in throat swab samples which were collected at least 24 hours apart;

(ii) Clinical remission of respiratory symptoms and fever for at least three consecutive days;

(iii) Substantial improvement of both lungs based on computed tomography.

All discharged patients remained on home isolation for another 14 days. 


\section{Supplementary Dataset 1}

This dataset shares our retrieved online records of 981 COVID-19 patients. Medical records from our local hospitals can be shared after the approval of the corresponding author and the Ethics Committees.

Please browse Full Text version to see the data of Supplementary Dataset 1.

Supplementary Dataset 1. This dataset shares our retrieved online records of 981 COVID-19 patients. 